\title{
Updated Interpretation of Magnetic Anomalies and Seafloor Spreading Stages in the South China Sea: Implications for the Tertiary Tectonics of Southeast Asia
}

\author{
ANNE BRIAIS ${ }^{1}$, PHILIPPE PATRIAT, AND PAUL TAPPONNIER
}

Institut de Physique du Globe de Paris

\begin{abstract}
We present the interpretation of a new set of closely spaced marine magnetic profiles that complements previous data in the northeastern and southwestern parts of the South China Sea (Nan Hai). This interpretation shows that seafloor spreading was asymmetric and confirms that it included at least one ridge jump. Discontinuities in the seafloor fabric, characterized by large differences in basement depth and roughness, appear to be related to variations in spreading rate. Between anomalies 11 and 7 (32 to $27 \mathrm{Ma}$ ), spreading at an intermediate, average full rate of $-50 \mathrm{~mm} / \mathrm{yr}$ created relatively smooth basement, now thickly blanketed by sediments. The ridge then jumped to the south and created rough basement, now much shallower and covered with thinner sediments than in the north. This episode lasted from anomaly $6 \mathrm{~b}$ to anomaly $5 \mathrm{c}(27$ to $-16 \mathrm{Ma})$ and the average spreading rate was slower, $-35 \mathrm{~mm} / \mathrm{yr}$. After $27 \mathrm{Ma}$, spreading appears to have developed first in the eastern part of the basin and to have propagated towards the southwest in two major steps, at the time of anomalies $6 \mathrm{~b}-7$, and at the time of anomaly 6 . Each step correlates with a variation of the ridge orientation, from nearly E-W to NE-SW, and with a variation in the spreading rate. Spreading appears to have stopped synchronously along the ridge, at about $15.5 \mathrm{Ma}$. From computed fits of magnetic isochrons, we calculate 10 poles of finite rotation between the times of magnetic anomalies 11 and $5 \mathrm{c}$. The poles permit reconstruction of the Oligo-Miocene movements of Southeast Asian blocks north and south of the South China Sea. Using such reconstructions, we test quantitatively a simple scenario for the opening of the sea in which seafloor spreading results from the extrusion of Indochina relative to South China, in response to the penetration of India into Asia. This alone yields between 500 and $600 \mathrm{~km}$ of left-lateral motion on the Red River-Ailao Shan shear zone, with crustal shortening in the San Jiang region and crustal extension in Tonkin. The offset derived from the fit of magnetic isochrons on the South China Sea floor is compatible with the offset of geological markers north and south of the Red River Zone. The first phases of extension of the continental margins of the basin are probably related to motion on the Wang Chao and Three Pagodas Faults, in addition to the Red River Fault. That Indochina rotated at least $12^{\circ}$ relative to South China implies that large-scale "domino" models are inadequate to describe the Cenozoic tectonics of Southeast Asia. The cessation of spreading after $16 \mathrm{Ma}$ appears to be roughly synchronous with the final increments of left-lateral shear and normal uplift in the Ailao Shan (18 Ma), as well as with incipient collisions between the Australian and the Eurasian plates. Hence no other causes than the activation of new fault zones within the India-Asia collision zone, north and east of the Red River Fault, and perhaps increased resistance to extrusion along the SE edge of Sundaland, appear to be required to terminate seafloor spreading in the largest marginal basin of the western Pacific and to change the sense of motion on the largest strike-slip fault of SE Asia.
\end{abstract}

\section{INTRODUCTION}

The South China Sea (Nanhai), and basins contiguous to it, cover a surface of $2.3210^{6} \mathrm{~km}^{2}$. They are the result of a large amount of extension, including the creation of seafloor, within a continental mass that may have extended from the Malay Peninsula to the Philippines between South China and the Sunda shelf. Extension started in the Paleocene and stopped in the middleMiocene [Taylor and Hayes, 1980, 1983; Hinz and Schlüter, 1985; $R u$ and Pigott, 1986]. A significant amount of shortening followed, mostly along the eastern and southern margins of the sea, from the middle Miocene to the present [Holloway, 1982; Fricaut, 1984]. Because the South China Sea is large and surrounded on three sides by large continental blocks, a quantitative understanding of its opening history is important for understanding the tectonics of Southeast Asia in Mid-Tertiary time.

Previous attempts to describe the formation and growth of the South China Sea [Taylor and Hayes, 1980, 1983; Holloway, 1982]

\footnotetext{
${ }^{1}$ Now at Observatoire Midi-Pyrénées, GRGS, Toulouse, France.
}

Copyright 1993 by the American Geophysical Union.

Paper number $92 \mathrm{JB} 02280$.

0148-0227/93/92-JB02280\$05.00 have been based on a limited number of marine profiles, on structural evidence along the margins, and on the directions of magnetic anomalies identified in the easternmost part of the sea. All these early attempts concur on a roughly N-S direction of seafloor spreading, and on a fixed position of Borneo and Indochina relative to South China during the opening of the sea. Combining predictions derived from laboratory models of the India-Asia collision with geological evidence suggesting that the Cenozoic tectonics of regions surrounding the South China Sea were dominated by leftlateral strike-slip faulting, Peltzer et al. [1982], Tapponnier et al. [1982, 1986] and Peltzer and Tapponnier [1988] have advocated a different view. They suggested that the collision between India and Asia had rotated and pushed Indochina and Borneo towards the SE, leading to the opening of the South China Sea and related basins as terminal pull-apart basins at the extremities of the Red River, Wang Chao and Three Pagodas faults. None of these studies, however, provided a complete, quantitative reconstruction of the opening of the South China Sea using the powerful constraints given by magnetic isochrons and seafloor fabric.

In this paper, we present an updated interpretation of the magnetic data in the basin, made possible by the detailed analysis of a dense new set of profiles [S.Chen, 1987] and discuss the implications of this interpretation for the evolution of the South China Sea 
spreading ridge. After recalling previous identifications of the magnetic anomalies in the basin, we describe our own identification of magnetic lineations. We then present the kinematic parameters of spreading computed from the fit of the magnetic isochrons and analyze the characteristics of the spreading and its evolution in space and time. Finally, we investigate whether the computed reconstruction of the opening of the basin is consistent with what is known of the deformation of the adjacent continental blocks. From this comparative analysis, we derive a sequence of schematic Tertiary palinspastic reconstructions of Southeast Asia. By including the geological evidence on sedimentary basins surrounding the area floored by oceanic crust, the reconstructions may be extrapolated to the initial stages of crustal extension, which led to the formation of the pull-aparts and rifts of the Sunda shelf and of the South China and North Borneo margins. Our palinspastic scenario is compared to scenarios based on different sets of data, concerning either the evolution of the west Pacific [Jolivet et al., 1989], or that of the India-Asia collision zone [Peltzer and Tapponnier, 1988].

\section{PREVIOUS STUDIES}

Since there exists no deep sea drilling core in the South China Basin, the identification of the magnetic anomalies provides the most important constraint on the age of the seafloor. Bowin et al. [1978] initially recognized magnetic lineations trending $N 70^{\circ} \mathrm{E}$ on a few profiles near Luzon Island. Taylor and Hayes [1980] then correlated magnetic profiles in the eastern part of the basin with a geomagnetic reversal time scale. They identified magnetic anomalies 11 to $5 \mathrm{~d}$, thus dating the seafloor to be between 32 and 17 million years old. With additional data, the same authors [Taylor and Hayes, 1983] revised their distribution of fracture zones, and discarded anomaly $5 \mathrm{~d}$ as reflecting only the disturbance by seamounts of the magnetics close to the ridge axis.

Insufficient evidence in the southwestern part of the South China Sea at that time prevented dating of that part of the basin. Taylor and Hayes [1983] nevertheless inferred the magnetic lineations to trend NE-SW, and heat flow measurements [Watanabe et al., 1977; Taylor and Hayes, 1983] suggested an early Miocene age. Since then, new magnetic profiles have been collected by the $R / V J$. Charcot during the French NANHAI and MASIN cruises, and by vessels from Chinese institutions (Figure 1). These profiles are an important addition to the set of available data, especially in the northwestern and southwestern subbasins, where the seafloor fabric and age were not constrained. Nevertheless, while all previous studies concur upon the Oligo-Miocene age of the eastern basin, with minor differences concerning the orientation of the magnetic lineations and the existence of a jump at the time of anomaly 7 [Taylor and Hayes, 1980, 1983; Watanabe et al., 1977; Lu et al., 1987], there is still no consensus about the age of the southwestern basin. Using data from new R/V R. D. Conrad cruises RC2612 and RC2614, Hayes et al. [1987] identify anomalies 6 to $5 \mathrm{~d}$ and thus infer a Miocene age for the southwestern part of the basin. In contrast, Lu et al. [1987], using the same set of Chinese data that we use in this study, infer a large age discrepancy between the eastern and southwestern subbasins. They identify anomalies 32 to 27 (70-63 Ma), oriented NE-SW, southwest of Macclesfield Bank, and anomalies 11 to 5D (32$17 \mathrm{Ma}$ ) to the east, with orientations swinging from ENE for anomalies 11-8 to E-W for anomalies 7-5d. Consequently, they distinguish three episodes of spreading in the evolution of the basin, the first in Cretaceous-Paleocene time, the last two in OligoMiocene time. The most peculiar feature of their analysis is the 30m.y.-long lapse in seafloor spreading in the early Tertiary.
The Sea Beam bathymetric data collected during the 1985 Charcot cruises revealed predominantly NE and NW striking topographic scarps in the $200-\mathrm{km}$-wide axial region of the entire South China Basin. This homogeneous fabric suggested that whether in the east or in the southwest the axial seafloor was generated by a spreading axis consisting of segments striking NE-SW [Pautot et al., 1986], dissected in the east by numerous right-lateral transform faults that maintain the overall E-W trend of the axis there [Briais et $a l ., 1989$ ]. Since no detailed information on the structural fabric of the seafloor exists farther off-axis to the north or south, correlating the magnetic anomalies between closely spaced profiles is the only way to constrain the direction of spreading and its evolution in time.

\section{MAGNETIC ISOCHRONS IN THE SOUTH CHINA SEA}

\section{New Data Set}

The most valuable new source of magnetic data is the map of closely spaced profiles compiled by S. Chen [1987] at the Second Marine Geological Investigation Brigade (SMGIB) of the Chinese Ministry of Geology and Mineral Resources (Figure 1). We digitized the magnetic anomaly profiles from the map, to obtain a set of data that could be easily projected and processed. With a mean spacing of 10 nautical miles $(-18 \mathrm{~km})$ between profiles, this data set is the first to provide resolution sufficient for a detailed and quantitative analysis of the evolution of the spreading ridge. The locations of the SMGIB, NANHAI and MASIN profiles are shown in Figure 1. In addition to these new data, our analysis includes the previously published Conrad and Vema profiles [Hayes and Taylor, 1978; Taylor and Hayes, 1980, 1983], which are not represented in the figures to keep them readable. The magnetic profiles drawn from the SMGIB map show good consistency with previous profiles guided by accurate satellite navigation. In particular, the SMGIB magnetic data match data from other cruises at crossing points, implying that the processing of the data and their drafting on the map are correct.

\section{Methods}

Our analysis of the magnetic anomalies in the South China Sea differs from previous analyses in three ways. First, we chose a geomagnetic time scale specifically adjusted for ridges with half spreading rates varying from less than $10 \mathrm{~mm} / \mathrm{yr}$ to $30 \mathrm{~mm} / \mathrm{yr}$, such as the Mid-Indian and South-Atlantic Ridges. The half rates of $20-30 \mathrm{~mm} / \mathrm{yr}$ inferred by Taylor and Hayes $[1980,1983]$ in the South China Sea fall within this range. Second, since the magnetic profiles are numerous, but the magnetic anomalies sometimes difficult to identify due to asymmetric spreading rates and ridge jumps, we systematically tested the magnetic isochrons by fitting identified conjugate isochrons. The goal was to obtain a good superposition of magnetic isochrons from either side of the axis, and to get a consistent series of isochrons, under the assumption that no major differential strain occurred within the oceanic crust since its creation. This combination of identifying the anomalies by comparison with synthetic profiles, and checking the identification by fitting the isochrons, helped us choose between alternative solutions in certain areas. Finally, we complemented the magnetic data with the stratigraphy of sediments covering the oceanic floor or deposited on the margins, the depth and structural fabric of the seafloor, the evolution of the margins as suggested by wells and subsidence studies, the heat flow and the free air gravity anomalies. Such additional data served to guide our final identifications and choose between various sequences implying different ages for the oceanic crust. 


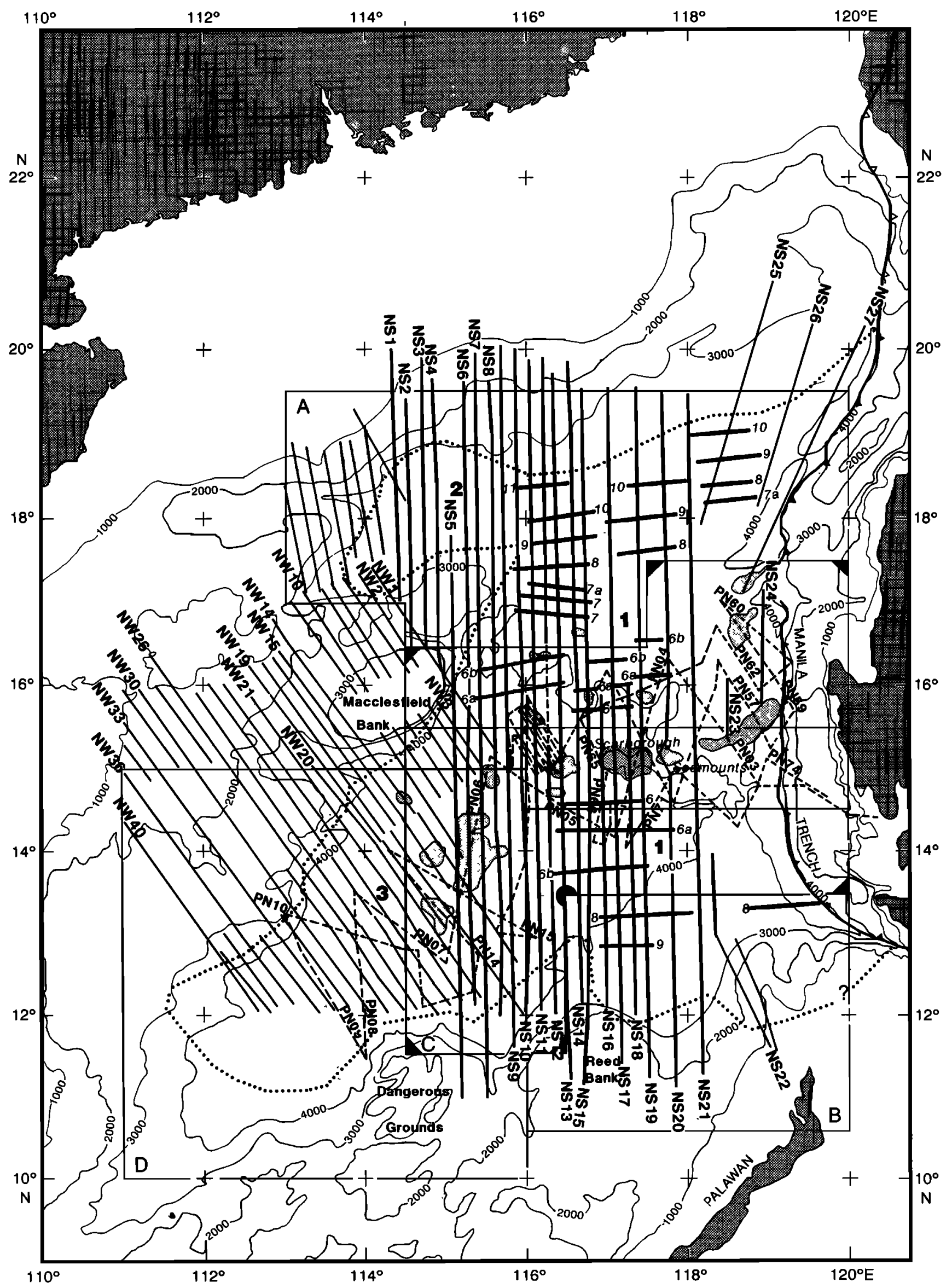

Fig 1 . Location and number of magnetic anomaly profiles used in this study. Solid lines are Chinese data (mostly from S.Chen [1987]), dashed lines French data. Magnetic anomalies identified by Taylor and Hayes [1983] are shown as bold lines. Dotted line is the approximate limit of oceanic crust. Areas 1, 2, 3 are eastern, northwestern and southwestern subbasins, respectively, as referred to in text. Bathymetry is in meters. Major seamounts are shaded. Boxes A to D show locations of Figures 3a, 3b, 6a, and $6 \mathrm{~b}$, respectively. 
This approach permits a coherent interpretation in small basins such as marginal seas, even though profiles are short and difficult to correlate with a unique sequence of magnetic reversals, especially when the axial age is unknown.

Taylor and Hayes [1980, 1983] chose to base their interpretation on the magnetic time scale of LaBrecque et al. [1977]. We have chosen to use a slightly modified version of the magnetic time scale described by Patriat [1987] (Table 1). In particular, the sequence of anomalies 5 to 13 was adjusted by Patriat [1987] so that synthetic magnetic anomaly profiles resemble profiles observed not only on fast and medium spreading ridges, but also on slow spreading ridges. The reversal time scale used here (Table 1, Figure 2) was mostly obtained by fixing the ages of major reversals in the succession of reversals described by Patriat [1987], so that in terms of absolute ages it is comparable to that of Berggren et al. [1985] (ends of anomaly 5: $10.42 \mathrm{Ma}$, anomaly 6: $20.45 \mathrm{Ma}$, anomaly 8: $27.74 \mathrm{Ma}$; beginning of anomaly 12 : $32.46 \mathrm{Ma}$ ). For the sequence of anomalies $5 \mathrm{c}$ to 13 , both the number of reversals and their relative ages differ between the scales of LaBrecque et al. [1977] and Patriat [1987] (Figure 2, Table 1). Both LaBrecque et al. [1977] and Patriat [1987] added short-period intervals ( $\leq 30,000$ years) to change the shape of certain anomalies, in order to obtain a better fit with observations. Short normal and reverse polarity intervals have been added at the times of anomalies $5 \mathrm{c}$ and $5 \mathrm{e}$, respectively, in Patriat's time scale, resulting in a change in the relative positions of reversals relative to LaBrecque's scale (Figure 2). Short reverse polarity intervals have also been added to the large normal interval of anomaly 6 , implying a lower relative amplitude for anomaly 6 and making anomalies $5 \mathrm{e}$ and $6 \mathrm{a}$ more distinct from anomaly 6 at slow spreading rates [Patriat, 1987] (Figure 2, Table 1). Both effects are observed on profiles in the Indian Ocean, where the spreading rate varies between 15 and $60 \mathrm{~mm} / \mathrm{yr}$, which suggests that Patriat's time scale is more reliable than previous ones for interpreting profiles from ridges spreading at rates of less than $60 \mathrm{~mm} / \mathrm{yr}$. In calculating synthetic profiles, we also have taken into account the fact that the change from one anomaly to the next along a magnetic profile generally results from a progressive, rather than sharp, contrast of magnetization between normal and reverse-polarity blocks [e.g., Schouten, 1971; Blakely and Cox, 1972; Tisseau and Patriat, 1981]. We used the method of artificial rates developed by Tisseau and Patriat [1981], in which an artificial spreading rate slower than that corresponding to the model is chosen, and the horizontal scale adjusted to restore the predicted length of the modeled magnetic profile. A prominent effect of this filtering is to produce loweramplitude anomalies, which are most often observed on slowspreading ridges.

The fit of conjugate magnetic isochrons is the best check of a good identification and yields the spherical parameters that describe the spreading quantitatively. We used two methods to fit the isochrons and calculate the poles and angles of rotation. The first method, introduced by Patriat [1987] and discussed by Sloan and Patriat [1992], is based on minimizing the misfit area obtained when matching the two lines defined by the picks of conjugate magnetic anomalies. Representative points are chosen on each isochron, to avoid disturbed areas such as transform offsets. Starting with a "first guess" pole, we compute the corresponding misfit, then those associated with a series of poles at a chosen distance (here $1^{\circ}$ ) from the first one. The pole that yields the smallest misfit is retained and the operation repeated. The search is complete when any pole at a chosen distance (here $0.1^{\circ}$ ) around the
TABLE 1. Magnetic Reversal Time Scale Used in This Study

\begin{tabular}{|c|c|}
\hline Normal Polarity Intervals, $\mathbf{M a}$ & Anomaly \\
\hline $10.36-10.42$ & 5 \\
\hline $10.54-10.60$ & \\
\hline $10.74-10.77$ & \\
\hline $11.04-11.11$ & \\
\hline $11.63-11.70$ & \\
\hline $11.94-12.19$ & \\
\hline $12.55-12.61$ & \\
\hline $12.88-13.03$ & \\
\hline $13.27-13.49$ & \\
\hline $13.76-14.04$ & \\
\hline $14.23-14.53$ & \\
\hline $14.74-14.84$ & \\
\hline $15.01-15.15$ & \\
\hline $15.38-15.42$ & \\
\hline $15.61-15.64$ & \\
\hline $15.84-15.88$ & \\
\hline $16.08-16.33$ & $5 c$ \\
\hline $16.47-16.57$ & \\
\hline $16.73-16.91$ & \\
\hline $17.11-17.14$ & \\
\hline $17.36-17.58$ & \\
\hline $17.63-17.81$ & $5 d$ \\
\hline $18.05-18.14$ & \\
\hline $18.44-18.70$ & $5 e$ \\
\hline $18.74-19.00$ & $5 e$ \\
\hline $19.26-19.40$ & 6 \\
\hline $19.44-19.54$ & 6 \\
\hline $19.58-19.72$ & 6 \\
\hline $19.76-19.96$ & 6 \\
\hline $19.99-20.19$ & 6 \\
\hline $20.22-20.45$ & 6 \\
\hline $20.73-21.02$ & $6 a$ \\
\hline $21.31-21.73$ & $6 a$ \\
\hline $22.00-22.18$ & \\
\hline $22.46-22.56$ & \\
\hline $22.86-23.03$ & \\
\hline $23.10-23.44$ & 6b \\
\hline $23.77-23.94$ & \\
\hline $24.07-24.32$ & \\
\hline $24.59-24.77$ & \\
\hline $25.74-25.85$ & 7 \\
\hline $25.91-26.10$ & 7 \\
\hline $26.51-26.69$ & \\
\hline $26.84-26.95$ & 8 \\
\hline $27.02-27.74$ & 8 \\
\hline $28.28-28.82$ & 9 \\
\hline $28.88-29.32$ & 9 \\
\hline $29.75-30.05$ & 10 \\
\hline $30.10-\mathbf{3 0 . 3 2}$ & 10 \\
\hline $31.34-31.62$ & 11 \\
\hline $31.72-32.09$ & 11 \\
\hline $32.46-32.96$ & 12 \\
\hline $35.51-35.71$ & \\
\hline $35.77-36.12$ & 13 \\
\hline
\end{tabular}

Bold: picked anomalies.

last selected leads to a larger misfit [Patriat, 1987]. The second method is an inverse method first described by Hellinger [1981], and refined by Chang [1987] and Royer and Chang [1991], who developed the software we used. The points at which isochrons are picked are grouped to define segments of either magnetic lineations or transform faults, paired before computation, and treated as arcs of great circles. The great circles and the rotation to fit them are determined by least squares. The misfit between the points and the great circles is used to compute the corresponding $95 \%$ confidence region, which represents the set of admissible poles and angles of 


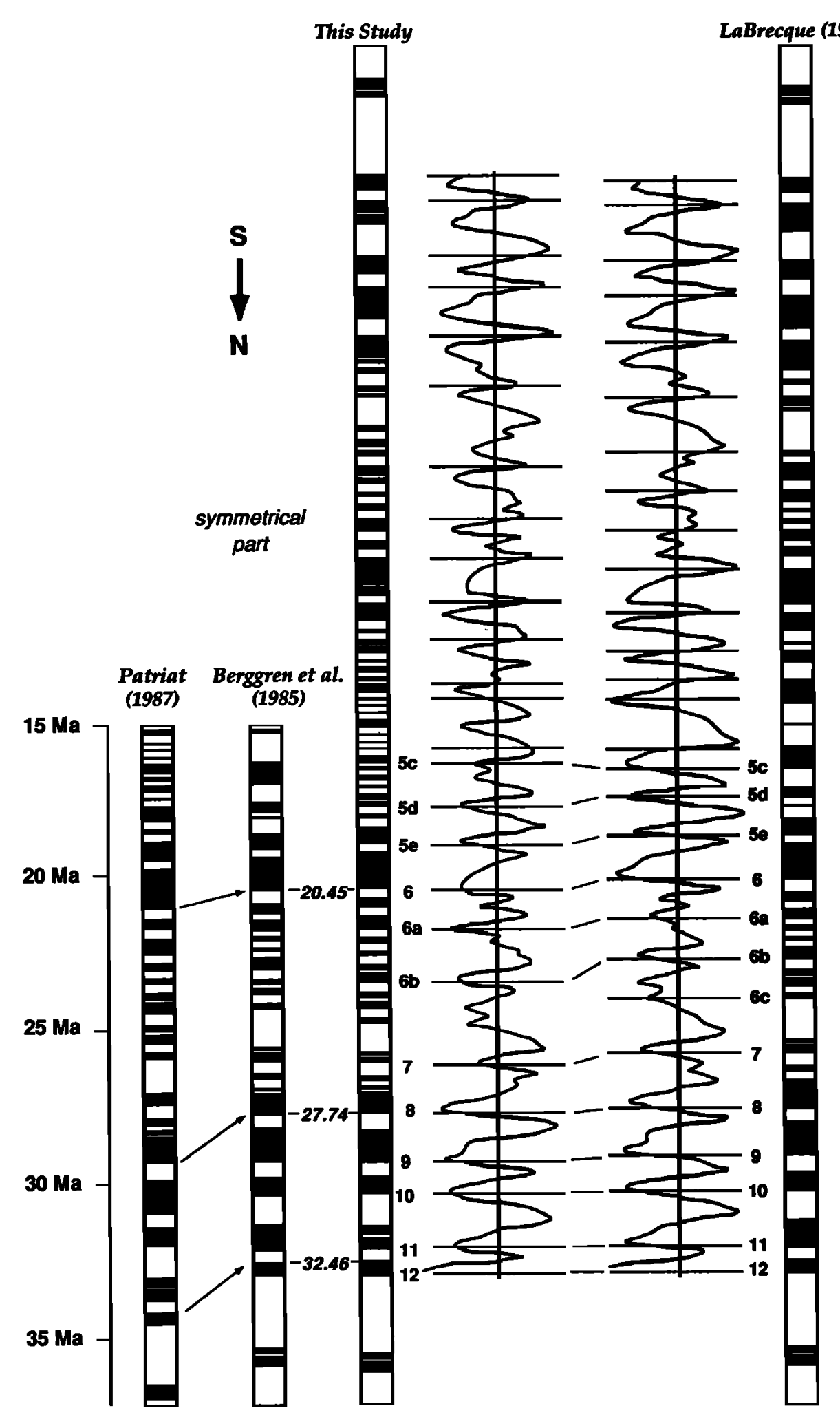

Fig 2. Comparison of magnetic reversal time scales. Normal polarity blocks are solid. Symmetric synthetic profiles calculated, for scales of $L a B r e c q u e ~ e t ~ a l$. [1977] and this study, assuming a 400 -m-thick magnetized layer under a ridge oriented E-W at $15^{\circ} \mathrm{N}$, $117^{\circ} \mathrm{E}$ since its creation.

rotations. The confidence region may be visualized as an ellipse in the latitude-longitude plane. It becomes very large when the angle of rotation is small. We used this method to visualize the confidence regions of the poles of rotations. A finite pole of rotation was obtained independently for each magnetic anomaly.
Stage poles, describing the rotation between two consecutive magnetic anomalies, were then computed to characterize, step by step, the evolution of the rate and direction of spreading.

Structural observations were used to separate the eastern, northwestern and southwestern oceanic subbasins (Figure 1), and to re- 
late the characteristics of the fabric of the oceanic crust in each basin to our model of magnetic isochrons. The location of the relict spreading axis corresponding to the last spreading episode was deduced from the bathymetry and the geometry of inward-facing normal faults observed on seismic profiles and Sea Beam swaths. In the southwest subbasin, this relict axis is also marked by a prominent free air gravity anomaly low [Taylor and Hayes, 1983; Pautot et al., 1986, 1990; Hayes et al., 1987]. Along the axial part of the eastern basin, the Scarborough seamount chain (Figure 1) probably lies on or close to the relict axis [Taylor and Hayes, 1983; Briais et al., 1989]. The fabric of the 200-km-wide axial part of that basin is characterized by a blocky basement, with normal faults striking ENE to NE and fracture zones striking NW, covered by a sedimentary layer about 0.5-s thick (two-way travel time) [Pautot et al., 1986, 1990; Briais et al., 1989]. North and southeast of the inferred relict spreading axis, the sediment thickness increases significantly, to 1.5-2 s (two-way travel time) and the basement becomes much smoother [Taylor and Hayes, 1983]. To the southwest, the fabric is characterized by normal fault scarps striking more homogeneously NE and fracture zone scarps striking NW [Pautot et al., 1986; Briais et al., 1989]. The northwestern subbasin is a deep, thickly sedimented oceanic trough between the passive continental margin of South China and the continental blocks of Macclesfield Bank and Paracels Islands. To the east, this trough is continuous with the deepest northern part of the eastern basin where Taylor and Hayes [1980, 1983] identified magnetic anomalies 8 to 11 (Figure 1). The large and sometimes sharp changes observed both in the seafloor fabric and in the sediment thickness, which suggest that the characteristics of the spreading changed abruptly in time during the opening of the basin, clearly represent first-order features to be explained by any kinematic model derived from the magnetic data.

\section{Identification of Magnetic Anomalies}

Estimation of the age and overall anomaly sequence in the eastern basin. The several attempts we made to fit the anomalies observed on the longest magnetic profiles from the eastern subbasin with sequences of the geomagnetic time scale confirm the Oligocene-early Miocene age of the sequence of anomalies, with spreading rates of the order of $20-30 \mathrm{~mm} / \mathrm{yr}$, as first inferred by Taylor and Hayes [1980, 1983] (Figures 3 and 4a). These ages postdate the rifting estimated to have started in the Paleocene-Eocene along the northern and southern continental margins of the eastern South China Sea [e.g., Holloway, 1982; Hinz and Schlüter, 1985; Fricaut, 1984; Ru and Pigott, 1986; Su et al., 1989]. The heat flow measurements are also consistent with an early to mid-Tertiary age for the ocean floor [Watanabe et al., 1977; Anderson, 1980; Taylor and Hayes, 1980, 1983]. The most typical sequence to be recognized in the basin is the $6 \mathrm{~b}-6$ anomaly sequence. It is especially prominent in the northeastern part of the basin (Figures 3 and 4). Nowhere else in the basin, to the south or southwest, is it found with the same typical shape (Figures 6 and 7). A priority in our interpretation of the anomalies in the eastern basin was to respect the broad shape of anomaly 6, which is characteristic in most oceanic basins [e.g., Patriat, 1987], as well as the large amplitude of anomaly 6b, which is prominent on both sides of the ridge (Figures 3, 4a, 6 and 7). It should be noted that the skewness is such that a given time in the magnetic time scale corresponds, within the uncertainty in picking of the anomalies, to a negative anomaly to the north of the profile, and to a positive anomaly to the south of the profile (Figures 2, 4 and 7).
Old crust in the eastern basin. The oldest magnetic lineations that could be identified are anomaly 11 in the north and 10 in the south (respectively, $32 \mathrm{Ma}$ and $30 \mathrm{Ma}$, Figures 3 and 4). Magnetic anomalies in the southeast have a lower amplitude than in the northeast, and anomalies 8 to 10 are not observed near the southeastern continental margin (Figures 3 and 4a). We discuss possible causes for this asymmetry in the section concerning reconstructions.

In the eastern basin, there is a greater number of magnetic anomalies north than south of the Scarborough relict axis (Figure 4a). This asymmetric distribution implies that the ridge jumped to the south, as Taylor and Hayes [1983] first inferred. Placing this jump just after anomaly 7 provides the best fitting synthetic magnetic profile (Figures 3 and 4a). The two conjugate anomalies 7 are observed in the north. To the southeast, anomaly 7 is missing, and the large-amplitude anomalies $6 \mathrm{~b}$ and 8 are juxtaposed (Figures 3 and 4a). A fanning of the magnetic lineations, spanning about $20^{\circ}$, is observed north of the ridge, revealing a change in the overall trend of the spreading center, from $N 70^{\circ} \mathrm{E}$ for anomaly 10 , to $\mathrm{N} 80^{\circ} \mathrm{E}$ for anomaly 8 , and to $\mathrm{E}-\mathrm{W}$ for the abandoned spreading center (Figure 3 ). This reorientation of the ridge system is accompanied by a reorganization of the ridge axis, which we shall discuss in the section on the evolution of the spreading system.

Northwestern basin. Previous data were too scarce to identify magnetic anomalies in the northwestern subbasin, although seismic data suggested that it is underlain by oceanic crust. The new profiles confirm this view and reveal symmetrically magnetized crust. Because this oceanic trough is particularly narrow $(\approx 150 \mathrm{~km})$, the correlation of observed profiles with a magnetic model is not unique (Figure 5). Nevertheless, only three sequences, consisting of anomalies $10-11,13-15$ or 21-22, provide an acceptable match to the observed profiles. Of these three possibilities, the $10-11$ sequence is most consistent with structural and stratigraphic observations, because it allows continuous spreading over the whole northern basin in the early Oligocene (Figures 3, 4a and 5).

Ridge jump at the time of anomaly 7 and correlative ridge reorganization. To the east, the ridge jump after anomaly 7 is confirmed by morphological observations of its effect on the ridge system. Since the conjugate anomalies 7 , which bound the abandoned ridge axis, are separated by the same distance all along that ridge, we infer that the jump was simultaneous for all segments. The eastern spreading segments, however, jumped farther south than the western ones (Figures 3 and $4 a$ ). The age difference at the boundary between the old and new crust is thus greater east of $117^{\circ} \mathrm{E}$ than to the west, as reflected by the larger topographic step observed between these crusts [Rea, 1978; Patriat, 1987] on seismic profiles (Figure $4 \mathrm{~b}$ ). The jump was accompanied by a reorganization of the ridge axis, characterized by the demise of the previous left-stepping geometry, and the formation of more continuous, mostly right-stepping axial ridge segments as observed on isochron $6 \mathrm{~b}$ (Figure 3 ).

The best-fitting synthetic profile also suggests a change in half spreading rate at the time of the jump, from $24 \mathrm{~mm} / \mathrm{yr}$ (in the west) to $29 \mathrm{~mm} / \mathrm{yr}$ (in the east) before the jump, to $19 \mathrm{~mm} / \mathrm{yr}$ after that jump (Figure 4a). We infer that the increase in the roughness of the seafloor observed on the seismic lines is due to the decrease in spreading rate (Figure 4b). A similar increase in the local roughness of the oceanic crust with decreasing spreading rate has been observed along the Indian Ocean ridges, which display half spreading rates varying from less than $10 \mathrm{~mm} / \mathrm{yr}$ to $20 \mathrm{~mm} / \mathrm{yr}$ and $30 \mathrm{~mm} / \mathrm{yr}$ for the Southwest, Central and Southeast Indian Ridges, respectively [Tapscott et al., 1980; Patriat, 1987]. 

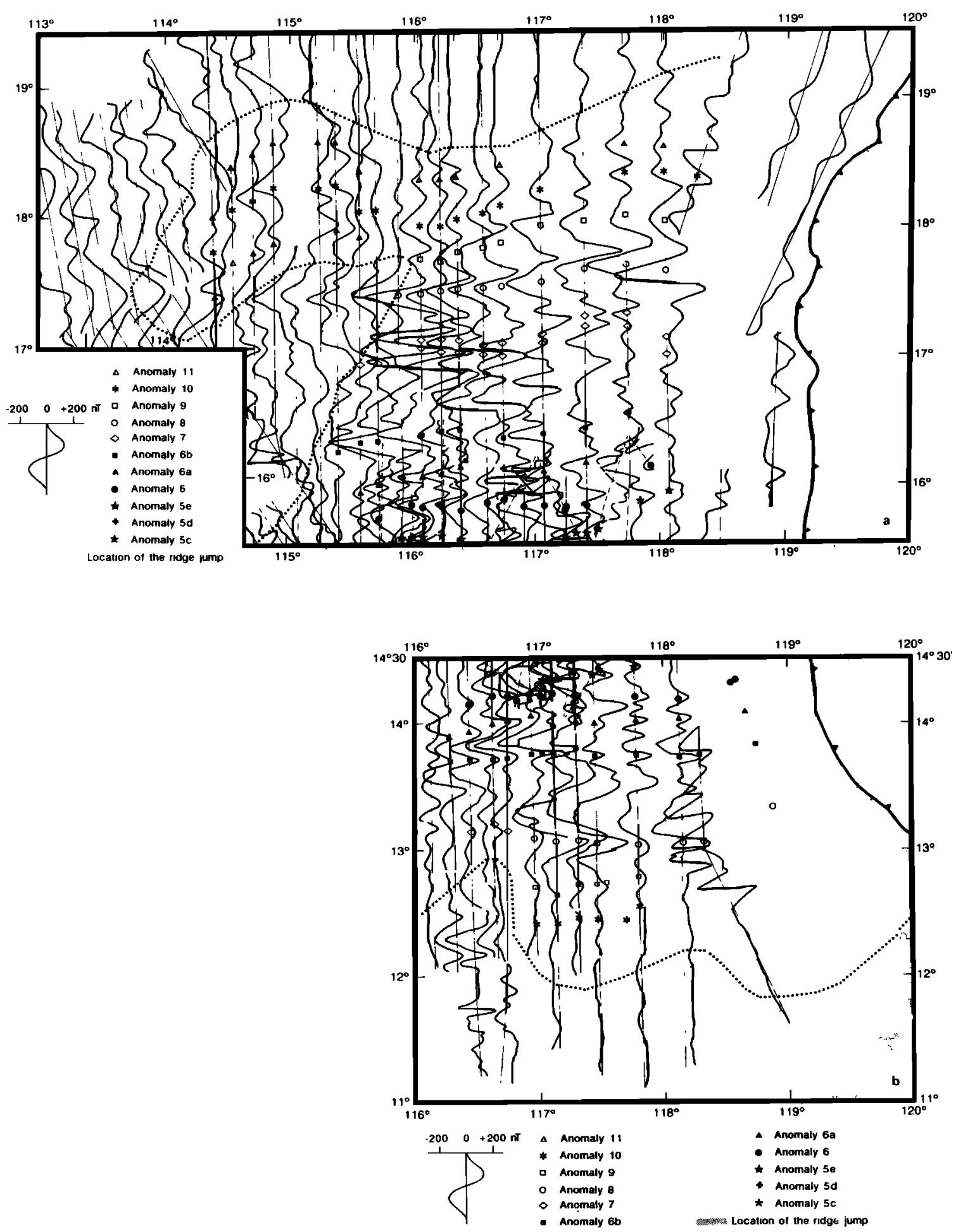

Fig. 3. Magnetic profiles plotted along ship tracks in (a) northern and (b) southern parts of eastern basin. Frames A and B in Figure 1. Barbed line is the Manila subduction zone. Dotted line is the inferred location of continent-ocean boundary. Symbols are the picks of anomalies identified in this study (and picks of anomalies on Vema profiles from Taylor and Hayes [1983]). Note the fanning of anomalies 11 to 7 , the southward ridge jump and the reorganization of spreading axis at time of anomaly 7 . Gray dashed line is the approximate boundary between the pieces of crust created before and after the ridge jump.

Short segments of isochron 7 are tentatively identified to the northwest and to the southwest, along the continental margins (Figures 3 and 4). The ridge therefore started to propagate towards the southwest, between Macclesfield Bank and Reed Bank, at that time.
Axial eastern area. In the eastern area, after the ridge jump, the magnetic isochrons appear to be more disrupted when approaching the axis (Figures 3 and 6). Taylor and Hayes [1983] inferred that disruption to result from the magnetization of the Scarborough seamounts, which were emplaced shortly after spreading stopped 

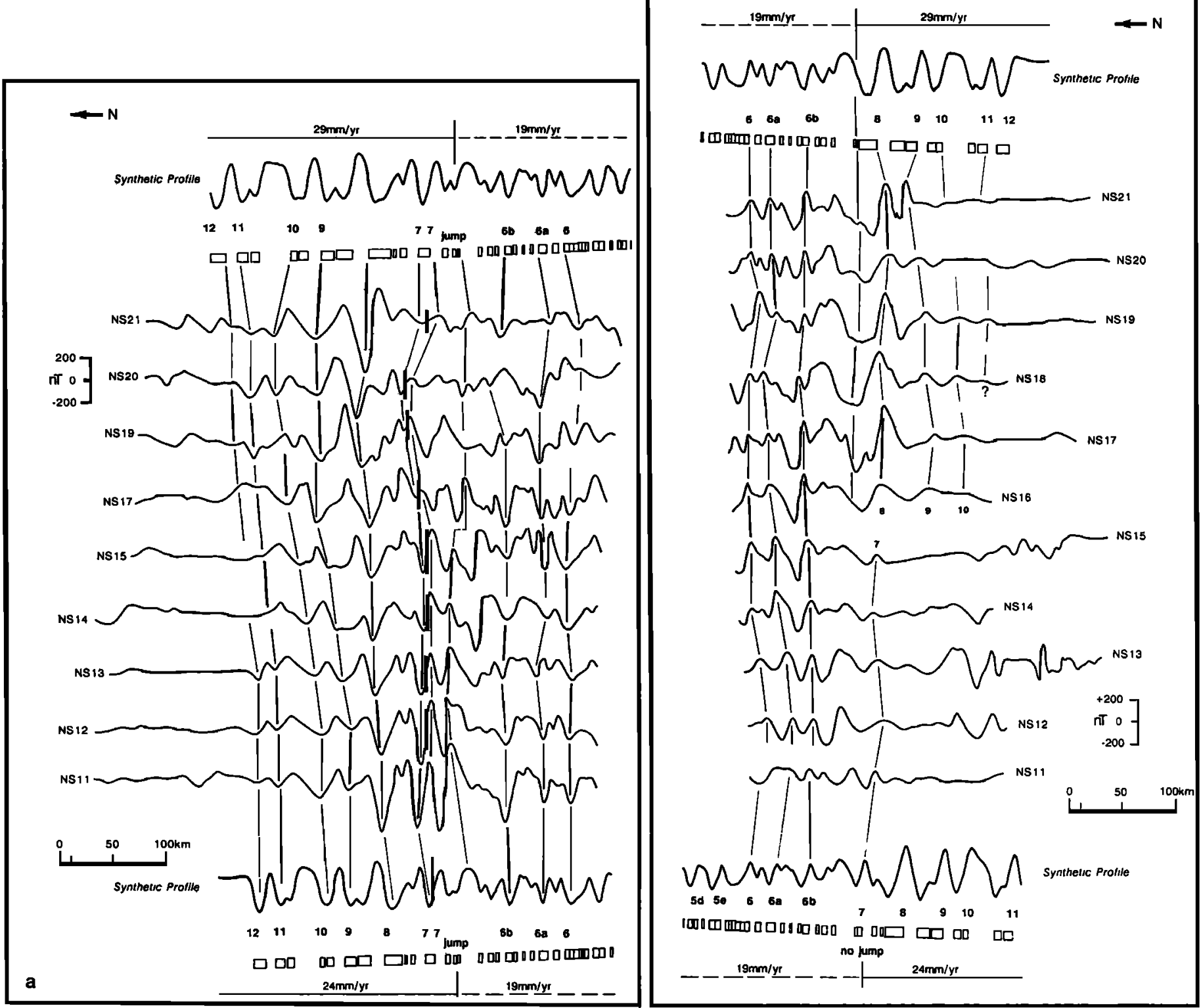

Fig. 4. (a) Identification of magnetic anomalies in (left) northern and (right) southern parts of the eastern basin, showing the ridge jump just after anomaly 7. Anomaly 7 is also tentatively identified on the southern parts of profiles NS11 to NS15. Data profiles are projected on $\mathrm{N} 180^{\circ} \mathrm{E}$ direction. Shown below the synthetic profiles are corresponding normal blocks in the time scale. (b) Seismic profiles [from Taylor and Hayes, 1983] and location of ridge jump identified from magnetics, showing the correlation of decreasing spreading rate with increasing basement roughness.

[e.g., Pautot et al., 1990]. This hypothesis, however, can only account for an abnormal magnetic signature close to the seamounts, while the anomalies seem to be distorted farther off-axis as well (Figure 6a). The disruption is thus more likely attributed to the geometry of the spreading axis itself, which includes numerous discontinuities [Briais et al., 1989].

For the sequence of anomalies $6 \mathrm{~b}$ to 6 in the eastern subbasin (Figure 7a), the eastern and western segments appear to have distinct behaviors. East of $117^{\circ} \mathrm{E}$, the best-fitting synthetic magnetic profile suggests that the magnetic sequences are rather symmetrical, with a half spreading rate of about $18-20 \mathrm{~mm} / \mathrm{yr}$. West of $117^{\circ} \mathrm{E}$, the best fit is obtained with a model involving a small ridge jump towards the south at anomalies $6 a-6$ time, and a half spreading rate of $19 \mathrm{~mm} / \mathrm{yr}$ (Figure 7a). Another possible model involves asymmetric spreading, with half spreading rates of $18-20 \mathrm{~mm} / \mathrm{yr}$ for the northern side of the ridge and $-12 \mathrm{~mm} / \mathrm{yr}$ for the southern side. We have a slight preference for the former model because it accounts best for the observation that anomalies 6 and $6 \mathrm{a}$ are represented by a total of 3 picks in the southeast and only 2 in the southwest, and that anomaly 6 is particularly large to the northwest (near $\mathrm{N} 15^{\circ} 30, \mathrm{E} 116^{\circ}$, Figures 6 and 7). This change in the behavior of the spreading center along strike probably explains why the $6 \mathrm{~b}-6$ sequence is more difficult to recognize south of the ridge than north of it, as initially noted by Taylor and Hayes [1980, 1983].

Southwestern basin. With the integration of the new profiles, the magnetic data in the southwestern subbasin have become especially dense, which frequently permits easy correlation of the anomalies between the profiles. That such a correlation is easier than in the central eastern basin suggests that the seafloor in the southwestern subbasin has been created along a spreading axis with 


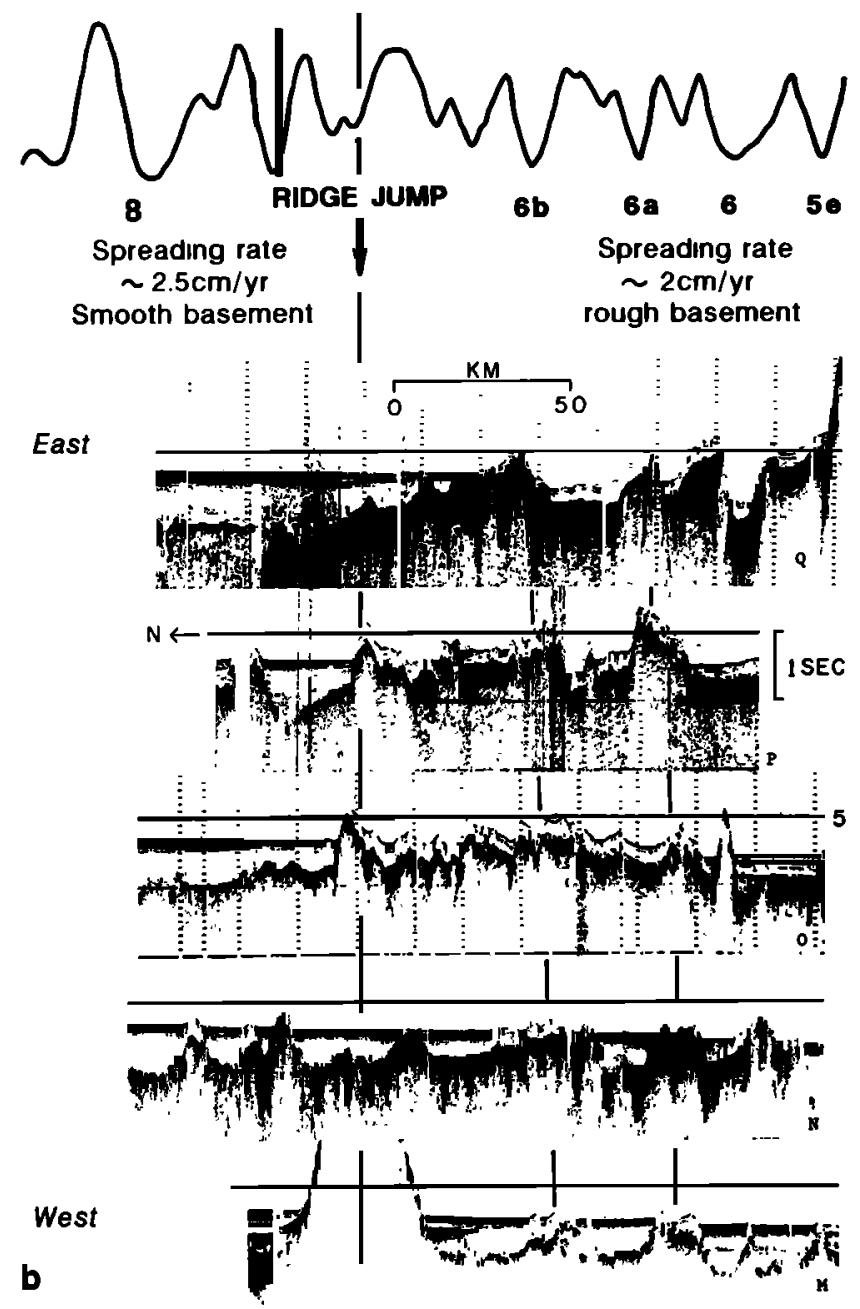

Fig. 4. (continued)

more simple geometry than that of the axis in the eastern basin. The prominent free air gravity anomaly provides the location of the relict spreading axis [Taylor and Hayes, 1983; Pautot et al., 1990]. As in the northwest, the narrowness of the oceanic crust in this subbasin, less than $150 \mathrm{~km}$ from the relict axis to the margin, makes the match of observed anomalies with a synthetic model nonunique. Four different sequences of anomalies, 6b-5c, 13-8, 19-13 and 26-21, of the reversal time scale provide synthetic profiles that resemble the observed magnetic profiles, with similar spreading rates, from 12.5 to $20 \mathrm{~mm} / \mathrm{yr}$ (Figure 8 ). Reconstruction of the geometry of the whole basin, however, permits us to tentatively choose between these sequences.

Inspection of the shapes of the anomalies initially led us to choose the sequence of anomalies 13 to 8 , with spreading rates of $17 \mathrm{~mm} / \mathrm{yr}$ in the north and about $11 \mathrm{~mm} / \mathrm{yr}$ in the south. This interpretation implied that spreading had ceased in the southwestern subbasin $10 \mathrm{~m} . \mathrm{y}$. before it did in the eastern one, and therefore that a major transcurrent zone existed near the boundary between the eastern and southwestern subbasins. A model in which the ridge was successively linked to eastward-jumping strike-slip faults could have accounted for such a pattern of spreading (Figure 9 inset). The uncontroversial identification of magnetic anomalies more recent than anomaly 7 in the eastern basin, and the reconstruction of its central part may be used to yield an image of the entire basin at the time when spreading would have ceased in the southwest, in that interpretation. This image (Figure 9) reveals a complex system
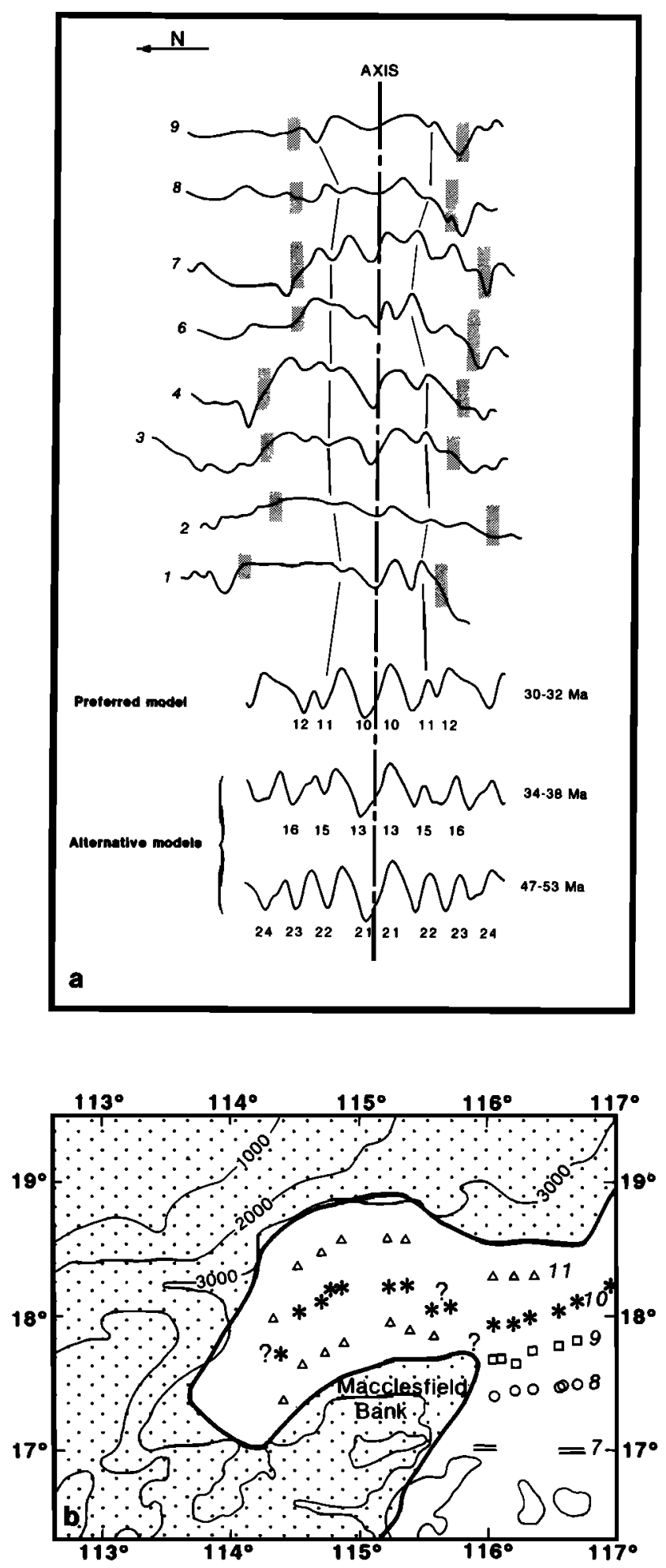

Fig. 5. (a) Identification of magnetic anomalies in the northwestern rift. Alternative synthetic profiles with an acceptable match with data are shown. Data profiles are projected on a $\mathrm{N} 160^{\circ} \mathrm{E}$ direction. Gray dashed line is approximate location of the continent-ocean boundary. (b) Location of identified magnetic anomaly picks, showing NE-SW orientation of rift. Bathymetry in meters.

of ridge segments, in which the central area is occupied both by an isolated, abandoned rift to the north and an intervening continental block (Macclesfield Bank) to the south. Clearly, our data are insufficient to argue for such complexity. 

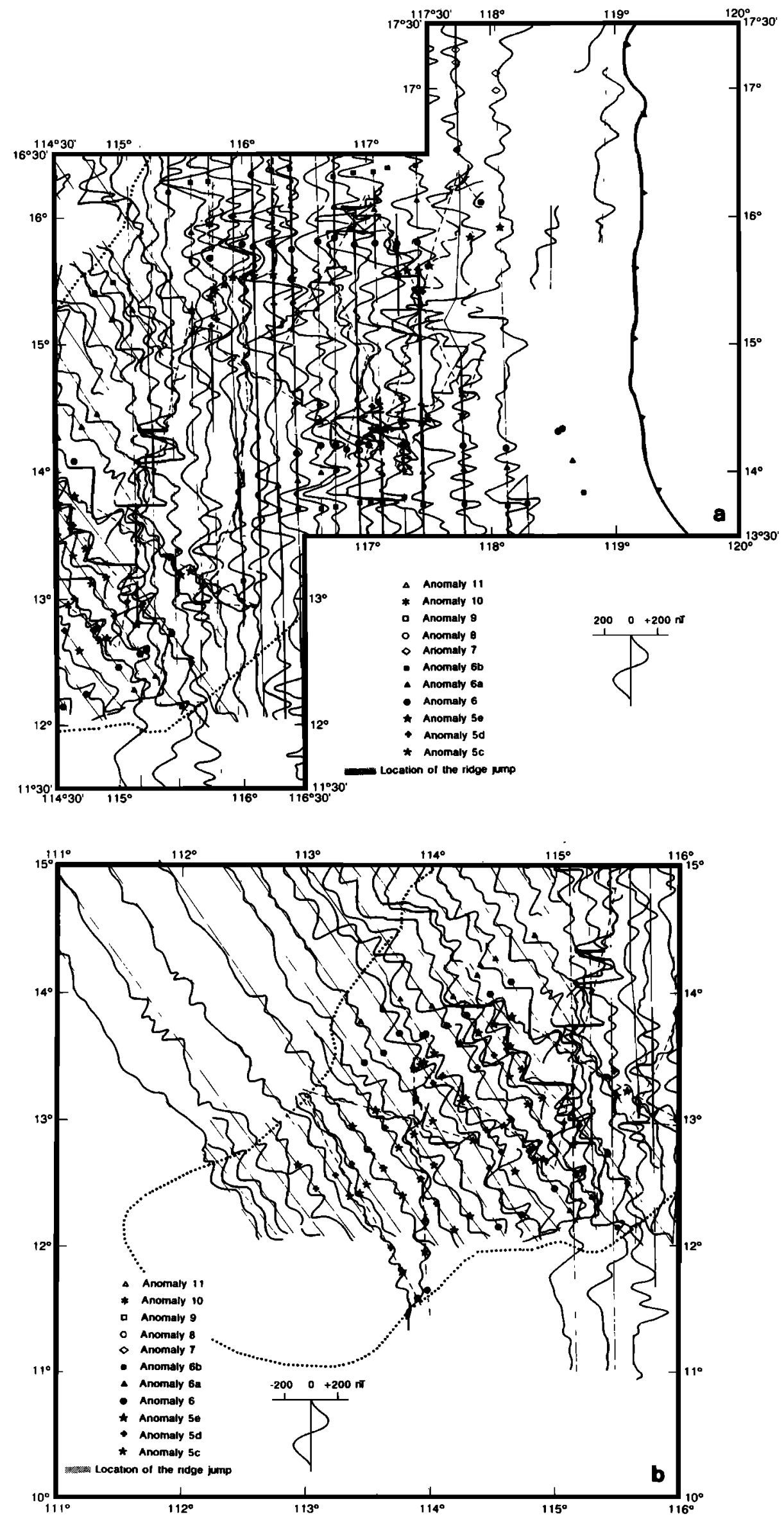

Fig. 6. Magnetic profiles plotted along ship tracks in axial area, (a) east and (b) southwest. Frames C and D in Figure 1. Dotted line is the inferred location of continent-ocean boundary. Barbed line is the Manila subduction zone. Symbols are the anomalies identified in this study. Note the stepwise southwestward propagation of oceanic spreading after anomaly 7. 


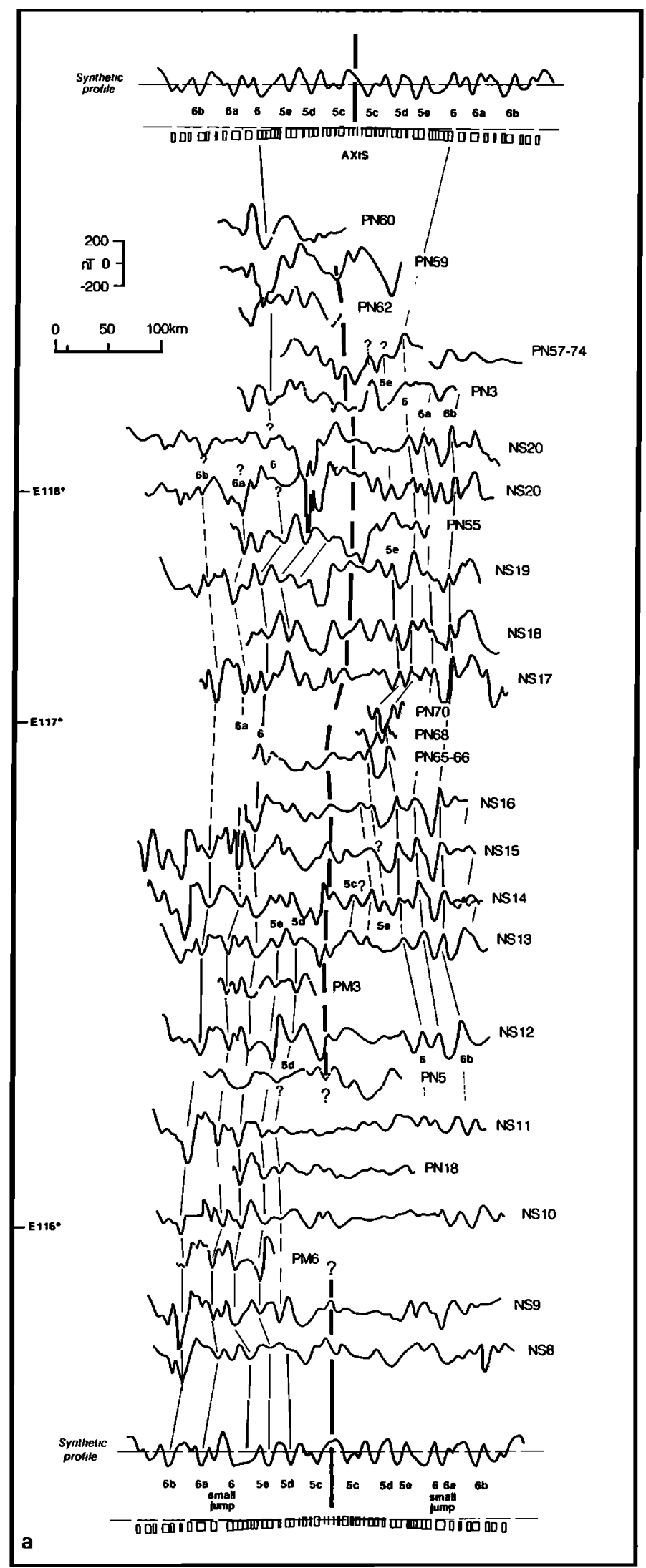

Fig. 7. Identification of magnetic anomalies in axial area of basin, (a) east, (b) intermediate, (c) southwest. Shown below the synthetic profiles are corresponding normal blocks in time scale. All models are calculated for half spreading rate of $19 \mathrm{~mm} / \mathrm{yr}$. Poor identification on profiles NS5-8 and NW1-13 reflects the complexity of the intermediate zone between Macclesfield and Reed Banks. The synthetic profiles at the bottom of Figures $7 \mathrm{a}$ and $7 \mathrm{~b}$ include ridge jumps at the time of anomalies $6 \mathrm{a}-6$ and $5 \mathrm{e}-5 \mathrm{~d}$, respectively, as discussed in the text. 


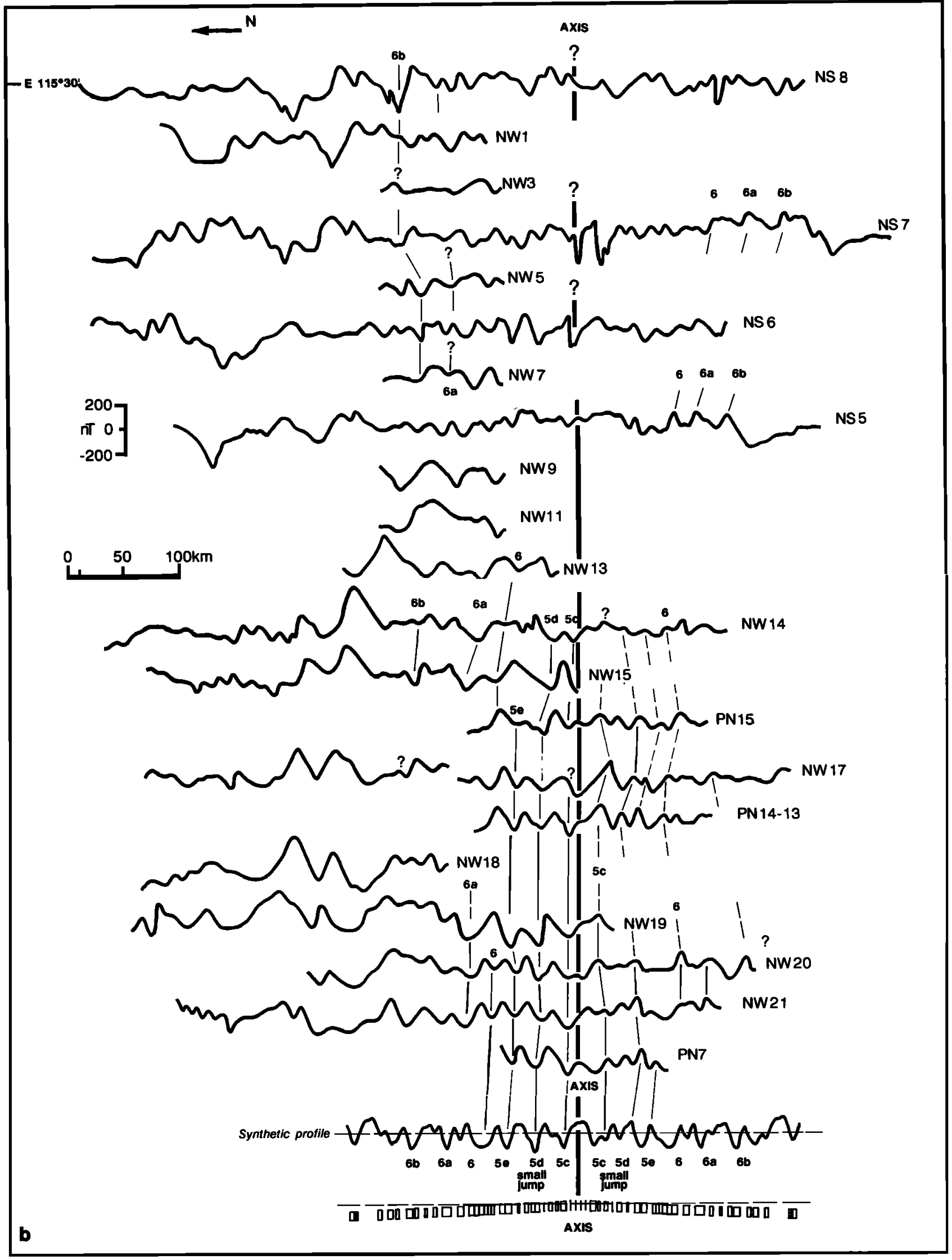

Fig. 7. (continued) 


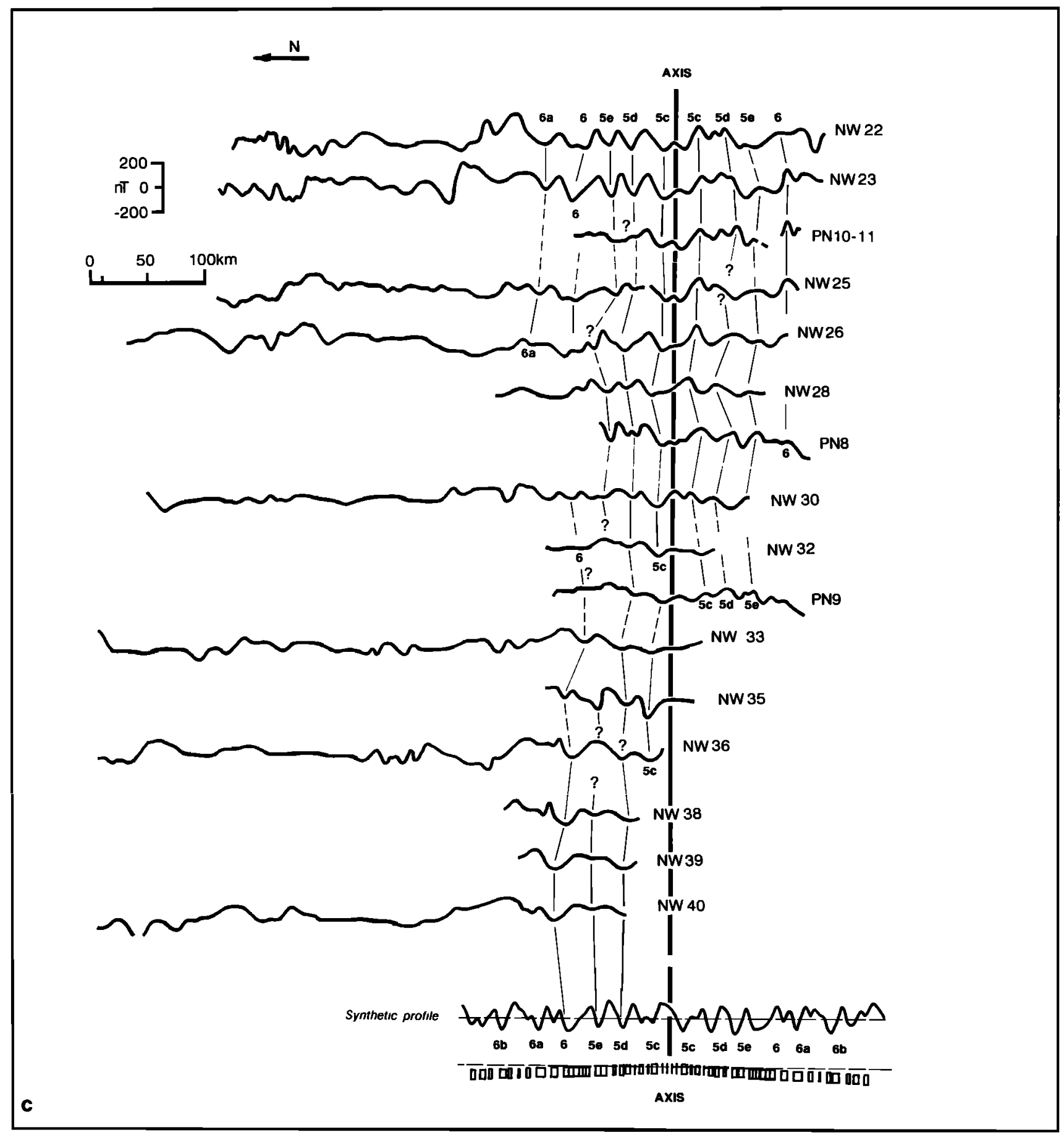

Fig. 7. (continued)

This led us to abandon our initial match and to opt for a match corresponding to the sequence of anomalies $6 \mathrm{~b}$ to $5 \mathrm{c}$ (Figures 6 and 7). The main advantage of this match is that it yields a simple, continuous geometry of magnetic isochrons across the whole central part of the basin. Moreover, fits of anomalies in the southwestern part, using poles of rotation computed only from anomalies identified in the eastern part, provide a positive test for the choice of the $6 \mathrm{~b}-5 \mathrm{c}$ sequence of reversals in the southwest. That we could obtain a consistent set of Euler poles of rotation, with reasonable confidence ellipses, for these anomalies is also an argument in favor of this choice. A problem that remains with this alternative match, however, is that the amplitude and shape of anomalies 6 to $6 \mathrm{~b}$ in the southwest are different from those of the same sequence in the east, where anomaly $6 \mathrm{~b}$ is so easily recognized (Figures 6 and 7). In fact, this new interpretation of the southwest subbasin now hinges on the series of anomalies observed on the northern side of profiles NW20-23, from anomaly $5 \mathrm{c}$, close to the axis, to anomaly 6 or $6 \mathrm{~b}$, close to the margin (Figures 6, 7b and $\mathrm{c}$ and 8).

The first identifiable anomalies along the margin are anomaly 6 in the southwest (west of $115^{\circ} \mathrm{E}$ ) and anomaly $6 \mathrm{~b}$ in the intermediate zone between the disrupted eastern and the southwesternmost axes (from $115^{\circ} \mathrm{E}$ to $116^{\circ} \mathrm{E}$ ) (Figures 6 and 7). This arrangement of the initial anomalies implies that the ridge propagated towards the 

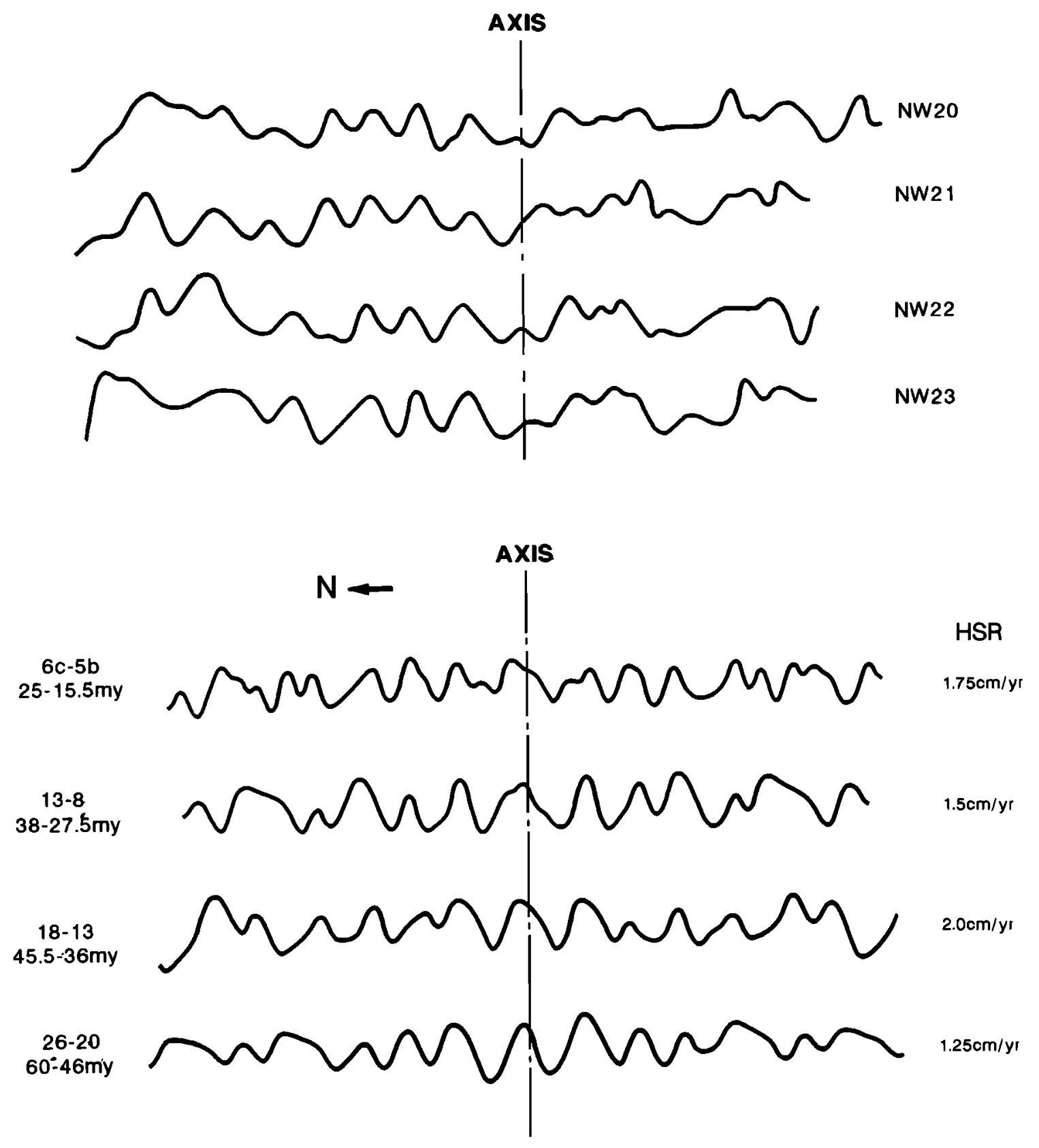

Fig. 8. Magnetic data profiles from (top) SW subbasin compared with (bottom) synthetic magnetic profiles corresponding to four different sequences of magnetic reversal time scale, showing that the interpretation is nonunique.

southwest in two major steps, first at the time of anomalies $6 \mathrm{~b}-7$, creating a new spreading axis in the intermediate zone, then at the time of anomaly 6 , when the ridge reached its longest extent. The poorly developed shape of anomaly $6 b$ in the southwest may be due to the fact that it represents the first anomaly along the margin, as does anomaly 11 to the northeast.

The best fit with a synthetic magnetic profile is obtained with a spreading rate of about $18 \mathrm{~mm} / \mathrm{yr}$ on either sides of the axis. Several profiles (NW20 to NW25, Figures $7 \mathrm{~b}$ and 7c), however, display prominent asymmetry. Synthetic profiles involving asymmetry in the spreading rates do not match the observations as well as models invoking a ridge jump. Our preferred model thus includes one more small ridge jump along the segment defined by these profiles at the time of anomaly $5 \mathrm{~d}$. As all other jumps inferred from magnetic anomalies in the South China Sea, that jump was directed toward the south.

Cessation of seafloor spreading. Because the axial part of the eastern basin does not display any identifiable magnetic anomalies, the last episode of spreading there may only be deduced from the model for anomalies $6-5 \mathrm{~d}$, assuming a constant spreading rate after anomaly $5 \mathrm{~d}$. This suggests a cessation of spreading near anomaly $5 c$ (Figure 7a). The anomalies observed in the axial zone show prominent variations of wavelength along strike (Figures 4 and 7), which may be interpreted in terms of differential asymmetric spreading related to the reorientation of spreading segments [Menard and Atwater, 1968; Hey et al., 1988]. In the southwestern part, the end of the spreading is observed just after anomaly $5 \mathrm{c}$ (e.g., on profiles NW19 to NW25, Figures 6 and 7). The simplest 


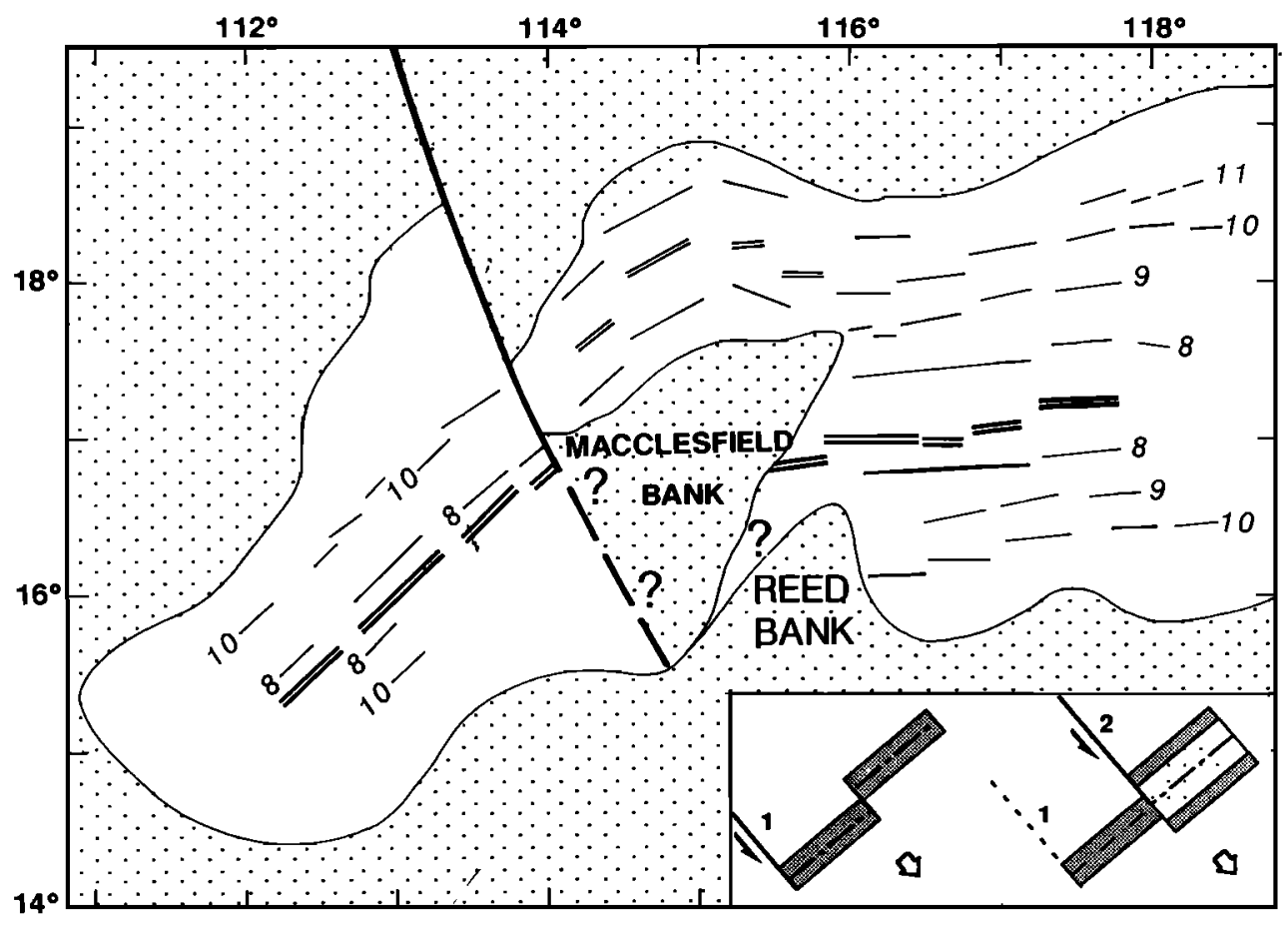

Fig. 9. Computed reconstruction of the central eastern basin at time of the ridge jump ( An7) showing complexities implied if sequence of anomalies 8-13 is chosen. Inset: Sketches depicting model of evolution of spreading in South China Sea assuming spreading, and associated strike-slip faulting, ceased earlier in the southwest (1) than in the east, due to the activation of a new strike-slip fault to the east (2).

conclusion is thus that the cessation of spreading in the South China Sea was synchronous all along the ridge, just after anomaly $5 \mathrm{c}$, at $\approx 15.5 \mathrm{Ma}$, although slight diachronism between the east and the southwest cannot be excluded. Note that this conclusion is a direct consequence of our preferred anomaly sequence match.

\section{RECONSTRUCTION OF SEAFLOOR SPREADING IN THE SOUंTH CHINA SEA}

The set of all the magnetic lineations deduced from the analysis described above is presented in Figure 11, along with all the tectonic features observed on Sea Beam swaths. The segmentation of the isochrons derives from the fits of magnetic anomalies identified on the profiles, resulting in the same shape of the isochrons on either side of the ridge. By fitting these magnetic isochrons we calculated the Eulerian poles of rotation. We present here the results of the fits and the reconstructions of the oceanic part of the basin, without considering the surrounding continental areas. We discuss the parameters of rotation calculated from these fits (Tables 2-4) and the major steps in the evolution of the spreading ridge (Figures 10-12). To assess the limit of the oceanic crust, we took into account the gravity anomalies defined in the gravity profiles of Taylor and Hayes [1983] and in the free air gravity anomaly map published by $B$. Chen et al. [1987]. We also took into account the magnetic profiles, especially along the northern and southwestern limits of the basin. The oldest, southeasternmost part of the oceanic crust in the basin appears to be partly concealed under a recent compressional thrust wedge and the thick sedimentation derived from it. That interpretation is supported by seismic evidence [Taylor and Hayes, 1983], and by the existence of a slice of Mid-Oligocene oceanic crust inferred to have been part of the South China Sea floor and obducted onto Mindoro Island in middle Miocene time [Rangin et al., 1985].

\section{Finite and Stage Poles of Rotation}

Using both Patriat's [1987] and Hellinger's [1981] methods, we adjusted the parameters of rotation to obtain a consistent set of stage poles, with no abrupt change in spreading direction and rate. The isochrons in a small ocean basin like the South China Sea are relatively short and close together, so that a simple best fit may lead to inconsistencies. To constrain the fit of anomalies older than anomaly 7 in the eastern basin, we thus used the additional observation that the anomalies abut the continental margin, west of Macclesfield Bank to the north and of Reed Bank to the south (Figure 11). The fit of magnetic anomalies younger than anomaly 7 is constrained by the elbow shape of the axis. The greatest uncertainty is in the central axial zone of the basin, due to the poor magnetic data and large number of seamounts. Hence as an additional constraint to fit anomalies $5 \mathrm{e}$ to $5 \mathrm{c}$ in this zone, we tried to respect the orientation of the fault scarps observed on Sea Beam bathymetric swaths (Figure 11). The only magnetic isochrons that are significantly offset by fracture zones are anomalies $10,6 \mathrm{~b}$ and $5 \mathrm{~d}$ (Figures 3, 6 and 11). The fact that we could clearly identify most of the segments of these anomalies on either side of the ridge provided a valuable constraint for the fit. Such a constraint could not be used for other isochrons, however, because they were either not disrupted by fracture zones, as in the case of anomalies 9 or 8 , or too disrupted by short-offset discontinuities, as for anomalies 6 to $5 \mathrm{~d}$ in the east.

Because small ridge jumps occurred at the times of anomalies 6 and 5d (Figure 7), the corresponding reconstructions are less certain than for other anomalies. Since the ridge jumps are small, 
TABLE 2. Finite Rotation Parameters

\begin{tabular}{lcccc}
\hline Anomaly & Age, Ma & Latitude, deg & Longitude, deg & Angle, deg \\
\hline \multicolumn{5}{c}{ Patriat's [1987] Method } \\
5c & 16.56 & -3.0 & 93.6 & 0.7 \\
5d & 17.81 & 5.0 & 105.5 & 3.7 \\
5e & 19.00 & -1.4 & 88.7 & 2.4 \\
6 & 20.45 & 0.1 & 83.3 & 2.8 \\
6a & 21.73 & 0.1 & 81.3 & 3.5 \\
6b & 23.44 & 7.1 & 75.9 & 3.9 \\
jump & 25.91 & 9.3 & 87.8 & 7.5 \\
8 & 27.74 & 8.2 & 91.2 & 10.3 \\
9 & 29.32 & 7.9 & 87.4 & 10.8 \\
10 & 30.32 & & 85.7 & \\
& & & 3.79 \\
5d & Hellinger's [1981] Method & & 2.72 \\
5e & 5.70 & 105.01 & 2.32 \\
6 & 0.09 & 92.26 & 3.26 \\
6a & 17.81 & -4.52 & 74.37 & 4.78 \\
6b & 19.00 & -0.50 & 78.60 & 10.98 \\
8 & 20.45 & 0.02 & 84.61 & 13.29 \\
9 & 21.73 & 9.73 & 92.95 & 11.20 \\
10 & 23.44 & 11.12 & 94.02 & 86.79 \\
\hline
\end{tabular}

Positive latitudes and longitudes are northern and eastern hemisphere, respectively.

TABLE 3. Stage Poles and Angles of Rotation

\begin{tabular}{|c|c|c|c|c|c|}
\hline Anomalies & Age End, Ma & Time Span, m.y. & Latitude, deg & Longitude, deg & Angle, deg \\
\hline \multicolumn{6}{|c|}{ Patriat's [1987] Method } \\
\hline End $-5 c$ & 15.64 & 0.69 & -3.0 & 93.6 & 0.7 \\
\hline $5 c-5 d$ & 16.33 & 1.48 & 6.7 & 108.2 & 3.0 \\
\hline $5 d-5 e$ & 17.81 & 1.19 & -12.9 & -47.8 & 1.6 \\
\hline $5 e-6$ & 19.00 & 1.45 & 7.3 & 58.0 & 0.5 \\
\hline $6-6 a$ & 20.45 & 1.28 & 0.4 & 72.9 & 0.7 \\
\hline $6 a-6 b$ & 21.73 & 1.71 & -7.2 & 39.1 & 0.6 \\
\hline $6 b-$ jump & 23.44 & 2.47 & 14.2 & 101.0 & 3.4 \\
\hline jump -8 & 25.91 & 1.83 & 14.3 & 101.0 & 3.3 \\
\hline $8-9$ & 27.74 & 1.58 & -10.7 & 2.7 & 0.7 \\
\hline $9-10$ & 29.32 & 1.00 & 4.4 & 55.8 & 0.6 \\
\hline $10-11$ & 30.32 & 1.77 & 10.9 & 84.9 & 1.4 \\
\hline \multicolumn{6}{|c|}{ Hellinger's [1981] Method } \\
\hline End $-5 d$ & 15.64 & 2.17 & 5.7 & 105.0 & 3.79 \\
\hline $5 d-5 e$ & 17.81 & 1.19 & -15.4 & -46.6 & 1.33 \\
\hline $5 e-6$ & 19.00 & 1.45 & -11.0 & -33.1 & 0.90 \\
\hline $6-6 a$ & 20.45 & 1.28 & 8.8 & 89.0 & 0.98 \\
\hline $6 a-6 b$ & 21.73 & 1.71 & 0.6 & 97.3 & 1.57 \\
\hline $6 b-8$ & 23.44 & 4.30 & 16.2 & 100.1 & 6.41 \\
\hline $8-9$ & 27.74 & 1.58 & 17.0 & 100.0 & 2.33 \\
\hline $9-10$ & 29.32 & 1.00 & -17.3 & -51.2 & 2.65 \\
\hline $10-11$ & 30.32 & 1.77 & 10.1 & 84.1 & 1.36 \\
\hline
\end{tabular}

Poles and angles computed for southern flank of the ridge from finite rotations in Table 2. Positive latitudes and longitudes are northern and eastern hemisphere, respectively.

however, they may be considered to reflect a mere asymmetry in spreading. We therefore include the results of the fits of anomalies $5 \mathrm{~d}$ and 6 , noting that the uncertainty for them is greater. The parameters of rotation at the time of the large jump after anomaly 7 are interpolated from those corresponding to anomalies 8 and $6 \mathrm{~b}$.

Since anomaly 11 is only tentatively identified on both sides of the narrow rift in the northwest, we calculated the pole of rotation corresponding to the stage between anomaly 11 and anomaly 10 , which forms the axis of that rift.

Uncertainties on the rotation parameters were computed using Hellinger's [1981] method. The results of the computations were unstable and varied as a function of the data points considered. The 95\% confidence ellipses are shown in Figure 12a. For anomaly $5 \mathrm{c}$, no acceptable confidence ellipse was obtained, although a good fit was reached using Patriat's [1987] method. The confidence el- lipses for anomalies 11 and 9 are very large. For anomalies 11 and $5 \mathrm{c}$, the conjugate picks are very close to one another, implying a very small rotation angle and therefore a greater uncertainty. For anomaly 9 , the great uncertainty is probably related to the shape of the isochron, which consists of short segments without significant offset. For other anomalies, the confidence ellipses are smaller (Figure 12a) but are always elongated in a direction parallel to the isochrons, which reflects the absence of large-offset transform faults, and the relatively short length of all the isochrons.

The finite poles of rotation are all located to the SW of the basin, the poles corresponding to anomalies 10 to 8 being closer to the basin than the poles corresponding to the younger phases of seafloor spreading (Figure 12a). The stage poles of rotation are much more scattered, but roughly aligned on a great circle. Using the main bathymetric features in the South China Basin and the 
TABLE 4. Directions (D) and Full Rates of Opening for Points in Southwestern (A) and Eastern (B) Parts of the Basin

\begin{tabular}{|c|c|c|c|c|c|c|c|}
\hline \multirow[b]{2}{*}{ Anomalies } & \multirow[b]{2}{*}{ Age end, Ma } & \multicolumn{3}{|c|}{ Point A } & \multicolumn{3}{|c|}{ Point B } \\
\hline & & $\Delta, \operatorname{deg}$ & $\mathrm{D}, \mathrm{deg}$ & Full rate, $\mathrm{mm} / \mathrm{yr}$ & $\Delta, \operatorname{deg}$ & $\mathrm{D}, \mathrm{deg}$ & Full rate, $\mathrm{mm} / \mathrm{yr}$ \\
\hline \multicolumn{8}{|c|}{ Patriat's [1987] Method } \\
\hline End $-5 c$ & 15.64 & 26 & -36 & 49 & 31 & -35 & 56 \\
\hline $5 c-5 d$ & 16.56 & 9 & -44 & 35 & 13 & -39 & 52 \\
\hline $5 d-5 e$ & 17.81 & 163 & -2 & 43 & 167 & 7 & 34 \\
\hline $5 e-6$ & 19.00 & 56 & 0 & 34 & 60 & 0 & 36 \\
\hline $6-6 a$ & 20.45 & 43 & -13 & 41 & 47 & -13 & 44 \\
\hline $6 a-6 b$ & 21.73 & 78 & -10 & 36 & 82 & -10 & 36 \\
\hline $6 b-$ jump & 23.44 & 14 & 11 & 36 & 17 & 3 & 45 \\
\hline jump -8 & 25.91 & & & & 17 & 4 & 60 \\
\hline $8-9$ & 27.74 & & & & 118 & 5 & 44 \\
\hline $9-10$ & 29.32 & & & & 63 & -2 & 62 \\
\hline $10-11$ & 30.32 & & & & 33 & -4 & $93(?)$ \\
\hline \multicolumn{8}{|c|}{ Hellinger's [1981] Method } \\
\hline End $-5 d$ & 15.64 & 12 & -37 & 40 & 16 & -35 & 55 \\
\hline $5 d-5 e$ & 17.81 & 162 & -10 & 39 & 166 & -3 & 30 \\
\hline $5 e-6$ & 19.00 & 149 & -1 & 36 & 152 & 5 & 32 \\
\hline $6-6 a$ & 20.45 & 26 & -6 & 37 & 30 & -8 & 42 \\
\hline $6 a-6 b$ & 21.73 & 21 & -32 & 36 & 25 & -31 & 44 \\
\hline $6 b-8$ & 23.44 & & & & 18 & 9 & 52 \\
\hline $8-9$ & 27.74 & & & & 18 & 14 & 52 \\
\hline $9-10$ & 29.32 & & & & 169 & -26 & 55 \\
\hline $10-11$ & 30.32 & & & & 34 & -5 & $92(?)$ \\
\hline $8-10$ & 27.74 & & & & 109 & -2 & 50 \\
\hline
\end{tabular}

Directions and rates computed from stage poles obtained with Patriat's [1987] method and Hellinger's [1981] method. Points A and B shown in Figure 11. D taken positive eastward. Symbol $\Delta$, distance between stage pole of rotation and point of measurement. Data for Hellinger's [1981] method, Point $B$, is used for Figure $12 \mathrm{~b}$.

geometry of the Red River Fault as first-order constraints, Peltzer and Tapponnier [1988] inferred the pole of finite rotation of Indochina relative to South China between 45 and $15 \mathrm{Ma}$ to lie at $7.5^{\circ} \mathrm{S}, 96^{\circ} \mathrm{E}$. This pole is located farther from the basin than the poles we calculated, and a few degrees south of them (Figure 12a). In their analysis of the paleogeographic evolution of the Southwest Pacific, Jolivet et al. [1989] estimated a pole of rotation (N39 , E176.25 $)$ for the stage of spreading after anomaly $6(20 \mathrm{Ma})$, the present-day trace of the Red River Fault being taken as a small circle. This pole lies north and east of the basin, very far from all the poles calculated here. The pole $\left(13.54^{\circ} \mathrm{S}, 2.63^{\circ} \mathrm{E}\right)$ they assumed for the first stage of spreading (32-20 Ma), on the other hand, is within a confidence ellipse of our results (Figure 12a). Le Pichon [1988] related all Cenozoic strike-slip movement within the Asian continent to rotation about a single pole, situated at $11^{\circ} \mathrm{N}, 95^{\circ} \mathrm{E}$, close to our results (Figure 12a).

\section{Major Stages of Seafloor Spreading}

The parameters of rotation are computed for each stage between successive anomalies from the sequence of finite poles. The rates and orientation of spreading for two points ( $A$ and $B$, Table 4, Figure 12b) now belonging, respectively, to the southwestern and eastern relict spreading axes are then computed from these stage poles. The directions of spreading shown in Table 4 are those computed from the rotation parameters, and are consistent with the orientation of the fabric measured on the structural maps for anomalies 6 to $5 \mathrm{c}$, following our choice to use this orientation as a constraint. From the beginning of the oceanic spreading (32 Ma) to anomaly $5 \mathrm{~d}(17.8 \mathrm{Ma})$, the full spreading rate decreases from more than $60 \mathrm{~mm} / \mathrm{yr}$ to about $35 \mathrm{~mm} / \mathrm{yr}$ (Figure 12b, Table 4). It increases back to about $55 \mathrm{~mm} / \mathrm{yr}$ between anomaly $5 \mathrm{~d}$ and the cessation of the spreading $(15.5 \mathrm{Ma})$. The differences in the directions of spreading estimated from the different methods of calculation of the poles of rotation (Table 4) give an idea of the uncertainty on the spreading direction, about $20^{\circ}$, leading to an uncertainty of about $5 \mathrm{~mm} / \mathrm{yr}$ in the spreading rate because of the induced obliquity.

Seafloor spreading began in the South China Sea at anomaly 11 (32 Ma). Anomaly 11 is not uniformly observed to the north, and not clearly observed in the south (Figures 3 and 10a), which suggests that the incipient ridge probably consisted of discontinuous spreading centers. A correlative explanation may be that the ridge jumped to the south between the times of anomalies 11 and 10 , leaving both sides of the incipient ridge to the north. Such a pattern of incipient oceanic spreading, source of atypical magnetic signatures, is observed in the northern Red Sea, where discontinuous volcanic centers disposed en échelon are creating the first basalt flows of the thinning continental margin [Cochran, 1983; Dixon et al., 1987]. The orientation of the ridge segments in the South China Sea, as drawn from the isochrons, varied from NE-SW to WNW-ESE. The direction of spreading was slightly west of north (Table 4, Figure 12b).

The spreading ceased in the northwestern subbasin just after anomaly $10(30 \mathrm{Ma})$. It continued farther to the east, however. The isochron drawn for anomaly 10 suggests that the ridge was segmented and that overall, the segments were arranged en échelon, into a right-stepping array (Figure 10b). The direction of spreading was close to N-S (Table 4, Figure 12b).

Between anomalies 10 and $7(30-26 \mathrm{Ma})$, fanning of the isochrons 10 to 8 (Figures 3 and 10c) implies a reorientation of the spreading system from an average ENE-WSW to an E-W direction, also suggested by the computed directions of spreading (Table 4, Figure 12b). Anomaly 8 appears to have been the most continuous isochron because the small fracture zones or discontinuities observed at anomalies 9 and 10 no longer disrupt it.

Between anomalies 7 and $6 \mathrm{~b}(26-24 \mathrm{Ma})$, the ridge jumped to the south, and then rapidly propagated to the southwest, resulting in a drastic change in the axis configuration. The beginning of the 

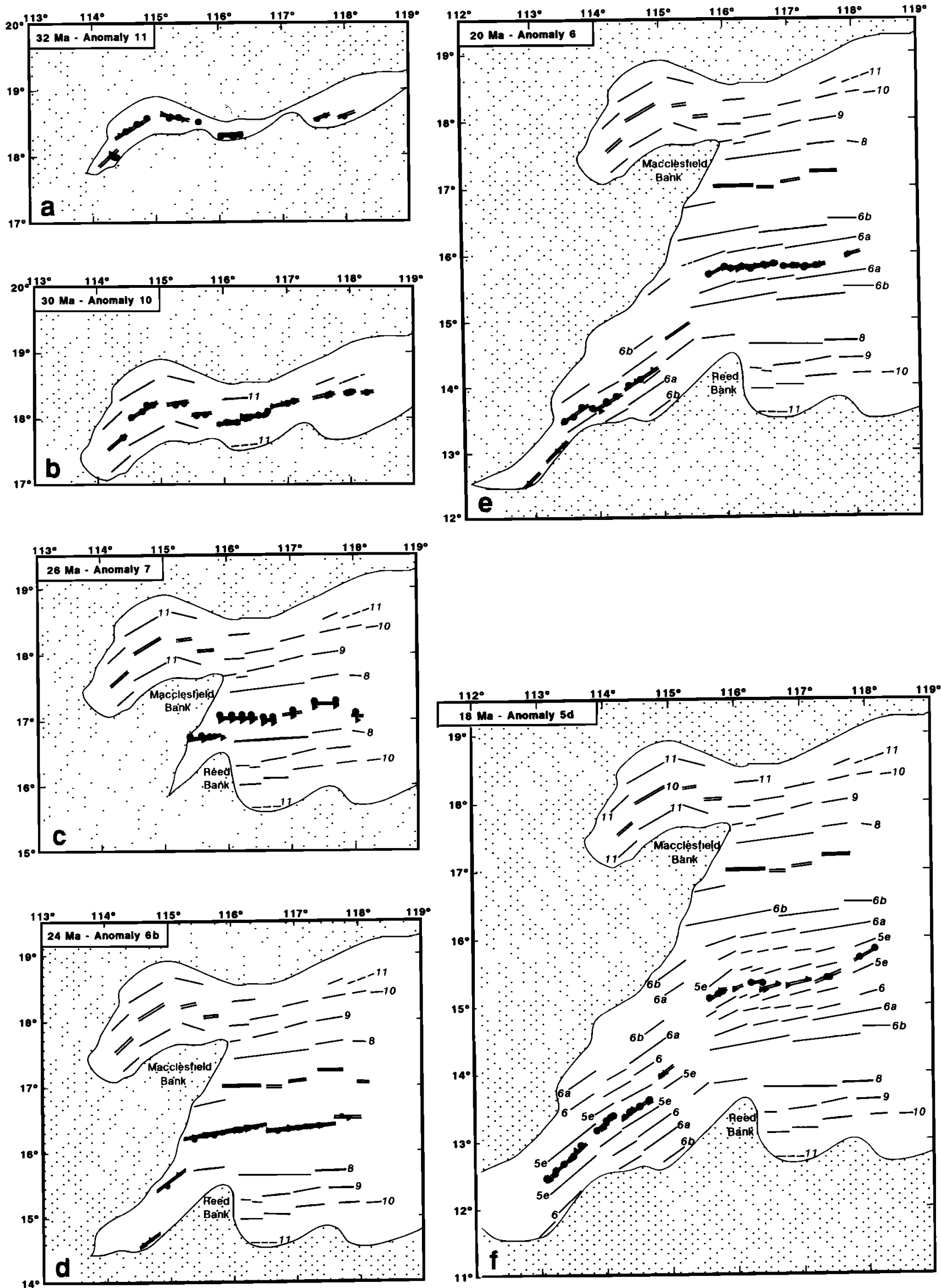

Fig. 10. (a)-(f) Fits of magnetic isochrons and approximate location of the continent-ocean boundary at time of An11, An10, ridge jump ( An7), An6b, An6 and An5d, respectively. Circles and triangles are the anomalies identified on the northern and southern sides, respectively. Dotted area is continental or stretched continental crust. Northern continental margin is fixed. 


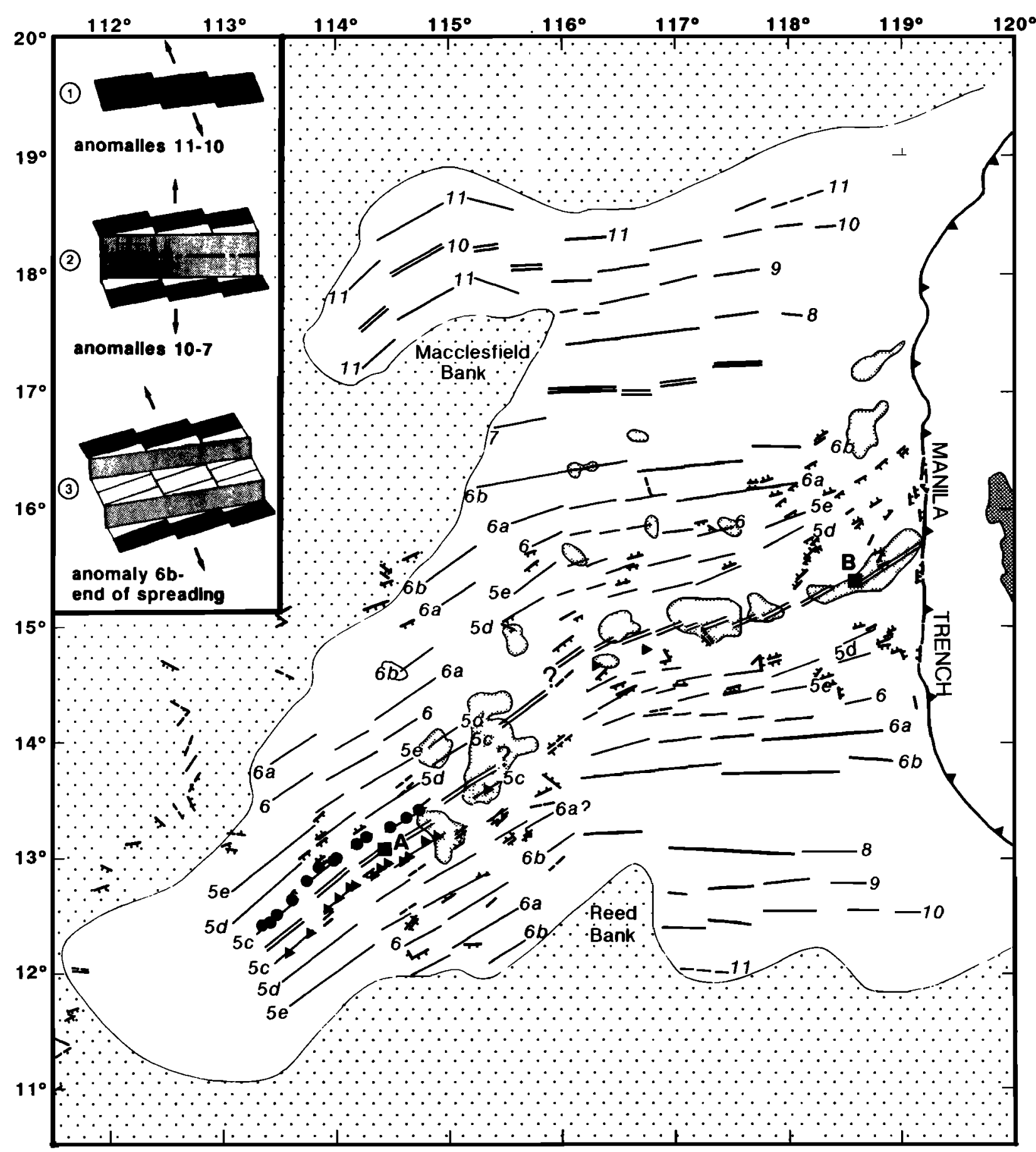

Fig. 11. Magnetic lineations in South China Sea from this study and fault scarps in axial area observed on Sea Beam swaths [from Brrais et al., 1989]. Inset: Sketch representing the evolution of ridge geometry in the eastern part of South China Sea, showing that segmentation accompanies changes in the direction of spreading while the overall ridge trend remains E-W.

propagation at the time of anomaly 7 is suggested by the identification of a small ridge segment between Macclesfield Bank and Reed Bank (Figures 3 and 10c). The $6 \mathrm{~b}$ isochron is well-defined in the east, with a configuration inherited from the ridge jump. To the southwest, it forms only short segments between Macclesfield and Reed Banks (Figure 10d). We cannot reconstruct the spreading geometry in the extremely disrupted zone around $\mathrm{E} 115^{\circ}$. Since a large offset is observed between anomalies in the east and in the southwest, this zone was probably characterized either by transform faults linked by short ridge segments, or by oblique segments with right-lateral normal slip. A high-resolution study of the bathymetry of this area would be necessary to choose between these geometries.

Anomaly 6 (20.5 Ma) corresponds to a second step of rapid propagation to the southwest, in which the ridge reaches its maximum extension. Given the available data, this corresponds to the maximum extension of the spreading system. The computed direction of spreading after the ridge jump (anomalies $6 \mathrm{~b}-6 \mathrm{a}$ ) is NW-SE, becomes closer to N-S around anomaly 6 , then changes back to NW-SE after anomaly 5e (Table 4, Figures 10e, $10 \mathrm{f}$ and 12b). 


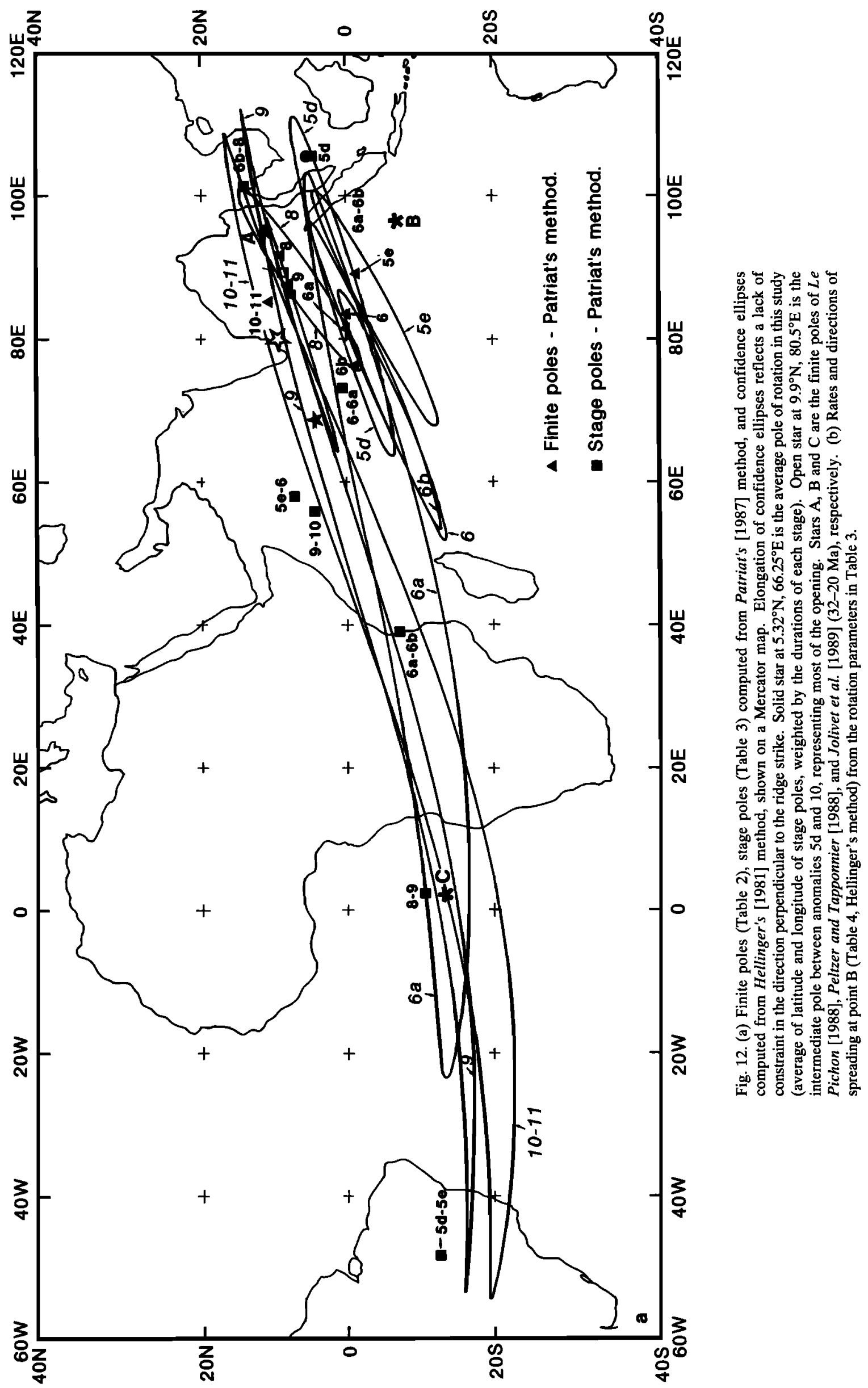



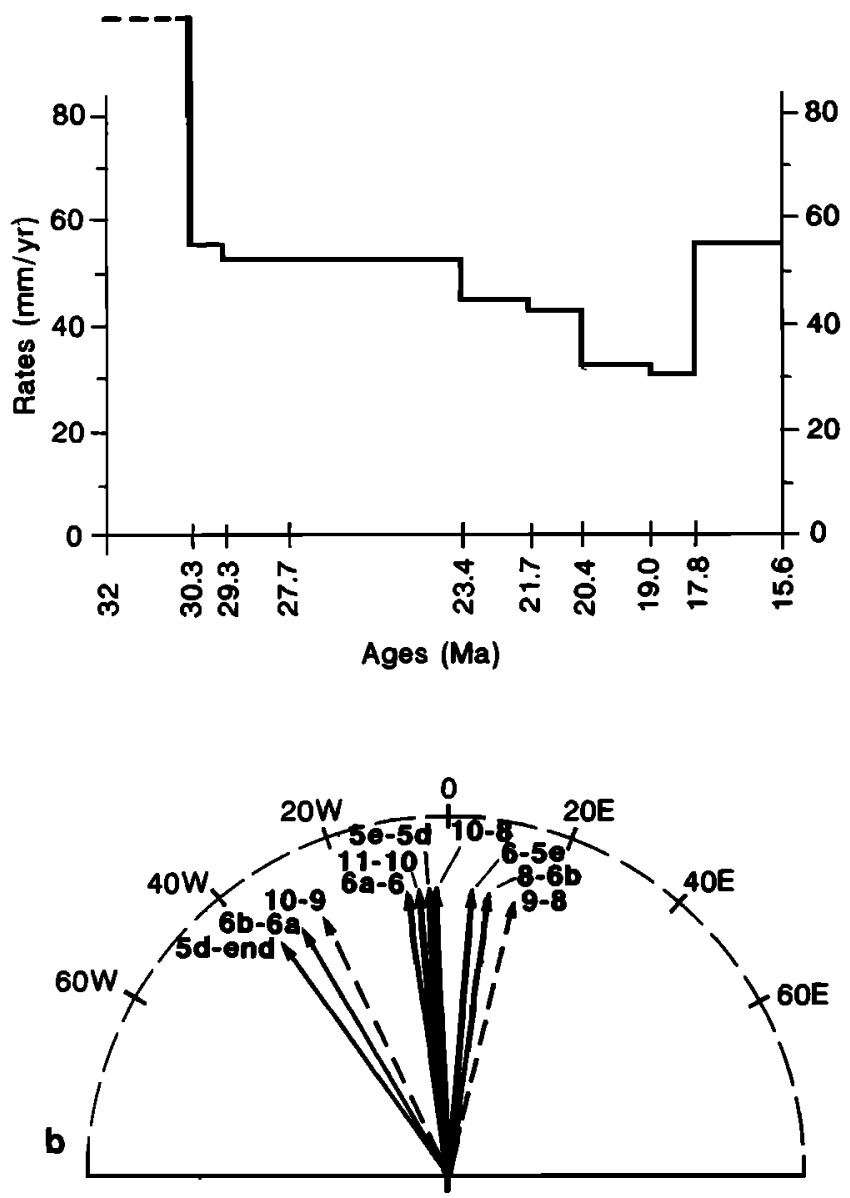

Fig. 12. (continued)

The time of anomaly 6 is also correlated with a reorientation of the spreading segments in the east, from $\mathrm{N} 80^{\circ} \mathrm{E}$ to $\mathrm{N} 60^{\circ} \mathrm{E}$ on average [Pautot et al., 1986]. At that stage, the ridge appears to have been segmented, probably more to the east than to the southwest. In both areas, however, the Sea Beam bathymetry reveals clear NE-SW normal fault scarps, but it does not show as many fracture zones as the offset of the magnetic isochrons might suggest (Figure 11). This implies that the spreading axis may have been offset along zones of rather diffuse deformation, which do not have a distinct bathymetric expression [Pautot et al., 1990]. At the time of anomaly $5 \mathrm{~d}(18 \mathrm{Ma})$ the orientation of the spreading segments was still changing, from $\mathrm{N} 70^{\circ} \mathrm{E}$ to $\mathrm{N} 50-40^{\circ} \mathrm{E}$, which lead to disrupted anomalies in the east (Figures $10 \mathrm{f}$ and 11; see Briais et al. [1989]). The direction of spreading was close to NW-SE (Table 4, Figure 12b).

Seafloor spreading probably stopped after anomaly 5c $(15.5 \mathrm{Ma})$ in the entire basin. In the southwest, that age is well constrained by the best-fitting synthetic magnetic profiles, given the anomaly sequence we chose. In the east, the axial area is occupied by the Scarborough seamounts chain. The emplacement of the seamounts is dated as $10-15 \mathrm{Ma}$ from dredged volcanics [Hekinian et al., 1989], and may have occurred along the relict spreading axis because it represented a weak zone in the oceanic crust [Briais et $a l ., 1989]$. The cessation of spreading seems to have occurred roughly at the same time throughout the basin. The extension stopped completely and was not taken up by another spreading ridge in the area, a fact that has strong implications for the reconstruction scenario.

\section{Characteristics of the Evolution of the Spreading System, a Discussion}

Direction of spreading and segmentation of the ridge. As mentioned earlier, anomalies 10 to 7 display a $20^{\circ}$ fanning that reflects a progressive change in the direction of the spreading axis. Also, while at the time of anomaly 10 the ridge appears to be segmented by several fracture zones, most of these zones disappear during the reorientation of the ridge, since anomaly 8 is more continuous. Similarly, the prominent disruption of the spreading axis starting after anomaly $6 \mathrm{a}$, with no clearly identifiable isochron segment younger than anomaly 6 , seems to be related to changes in the direction of spreading. The segments that form the successive ridges appear to become shorter as their orientation changes from $\mathrm{N80}{ }^{\circ} \mathrm{E}$ at the time of anomaly $6 \mathrm{a}$, to $\mathrm{N} 50^{\circ} \mathrm{E}$ at the time of anomaly $5 \mathrm{~d}$. Such a segmentation of the axis is consistent with the observation of truncated ridges on the Sea Beam bathymetry in the eastern axial region, as well as with the observation that seamounts in this region are elongated in the $\mathrm{N} 50^{\circ} \mathrm{E}$ and $\mathrm{N} 140^{\circ} \mathrm{E}$ directions [Briais et al., 1989; Pautot et al., 1990]. Hence in the eastern basin, segmentation appears to accompany changes in the spreading direction, while the overall ridge orientation remains E-W (Figure 11, inset). This is probably because the overall direction of the ridge is inherited and controlled by the geometry of the margin, which is close to E-W.

Different models have been proposed for small-scale reorientation of spreading centers. One model [Menard and Atwater, 1968] invokes progressive rotation of the ridge, with shortening or lengthening of the segments according to the geometry before and after reorientation. Another model suggests that reorientation occurs as a new spreading direction forces spreading centers to propagate along a new trend while those corresponding to the old spreading direction gradually die out [Hey, 1977; Hey et al., 1988]. The fact that the ridge jumped to the south at the time of anomaly 6a-6 in the eastern South China Sea (Figure 7a) may imply that the reorientation of the ridge preferentially involved small-scale propagation of spreading centers towards the southwest, thereby transferring part of the older crust to the northern plate.

The evolution of the spreading ridge derived from the magnetic anomalies confirms changes in the direction of spreading (Figure 12b), that had been suspected but not demonstrated by earlier studies [Pautot et al., 1986, 1990; Hayes et al., 1987]. The computation of the parameters of spreading at two points of the spreading system (Table 4), however, suggests that, in general, the ridge segments were probably not perpendicular to the spreading direction, even in the last stages of the spreading. A detailed study of the topography would be necessary to model further the evolution of the ridge, especially in the area younger than anomaly $6 \mathrm{~b}$, where a progressive reorientation of the spreading system is strongly suspected.

Asymmetric spreading, ridge jumps and ridge propagation. In addition to the major ridge jump just after anomaly 7 , the evolution of the South China spreading center seems to have been characterized by small ridge jumps, always to the south, and by a systematic asymmetry of spreading, rates to the north generally being greater than to the south. Relative to South China, this asymmetry reflects a southward motion of the ridge faster than that due only to spreading. Stein et al. [1977] have shown that migration of a spreading ridge with respect to the deep mantle might induce asymmetry, with faster spreading on the trailing side. In all models of 
opening of the South China Sea, the smaller southern plates are implicitly assumed to have a greater absolute motion (relative to the deep mantle) than the larger northern plate (Eurasia). In other words, as the South China Sea spreading center was moving south relative to South China (Eurasia), it also moved south relative to the deep mantle. The asymmetry observed in the basin is thus that expected from the qualitative model of Stein et al. [1977].

The ridge jump observed at the time of anomaly 7 seems too large to be linked with the asymmetry of the extension in the basin. Rather, it probably reflects a change in the geodynamic boundary conditions prior to the propagation of the ridge towards the southwest, that may have triggered both the jump and the propagation. An attempt to reconstruct the ridge at the time of the jump reveals that the old and new crusts overlap, implying that the old and the new ridges were simultaneously spreading for some time before the old one died out. That ridge jumps are progressive and not instantaneous is widely documented in other oceanic basins.

One consequence of the propagation of a rift is the wedge shape of the continent-ocean boundary due to the progressive tearing of the continent [e.g., Courtillot, 1982, Courtillot et al., 1984]. The irregular, stepwise decrease of the area floored by oceanic crust toward the SW suggests that ridge propagation occurred in a discontinuous fashion. It was fast between anomalies 7 and $6 \mathrm{~b}$, rather slow between anomalies $6 \mathrm{~b}$ and $6 \mathrm{a}$, and then accelerated again before anomaly 6 (Figures 10 and 11).

\section{COMPATIBILITY WITH SURROUNDING CONTINENTAL TECTONICS: DISCUSSION AND IMPLICATIONS FOR THE TERTIARY EVOLUTION OF SOUTHEAST ASIA}

In this section we try to relate quantitatively the unusual evolution of the South China Sea spreading system with the Tertiary tectonic evolution of the continental areas surrounding that sea. In regions such as the western Pacific, it has become clear that the opening of marginal basins is a three-dimensional problem, and that the local relationship between back arc extension and nearby subduction has to be integrated into a larger-scale plate tectonic framework [e.g., Tapponnier et al., 1982, 1986; Peltzer and Tapponnier, 1988; Jolivet et al., 1989]. An important problem in reconstructing seafloor spreading in the South China Sea is that the spreading centers that led to its opening formed, evolved for -15-20 m.y. and "peacefully" died out while being surrounded to the north, west and south by large continental blocks. Clearly, a prerequisite to constrain the tectonic history of the South China Sea is a three-dimensional understanding of the large-scale Tertiary tectonics of its continental surroundings.

\section{Opening of the South China Sea Within the Framework of Asian Tectonics}

Given that the present-day orientation of extensional troughs north and south of the basin, and of the relict spreading axis, is almost perpendicular to the Vietnam coast, all models of opening of the South China Sea postulate the existence of a major transcurrent system west of the basin (Figure 13). Since several deep sedimentary troughs parallel the Chinese margin, initial rifting is thought to have involved mostly normal faults along this margin, hence mostly strike-slip faults along the Vietnam margin. From a kinematic point of view, it is possible either that the rifts terminated against a rightlateral fault following that margin (Figure 13a), with only small fragments detached from the Chinese continent sliding south along it [Holloway, 1982; Taylor and Hayes, 1983; Lu et al., 1987], or that left-lateral strike-slip faults from within the continent propa-
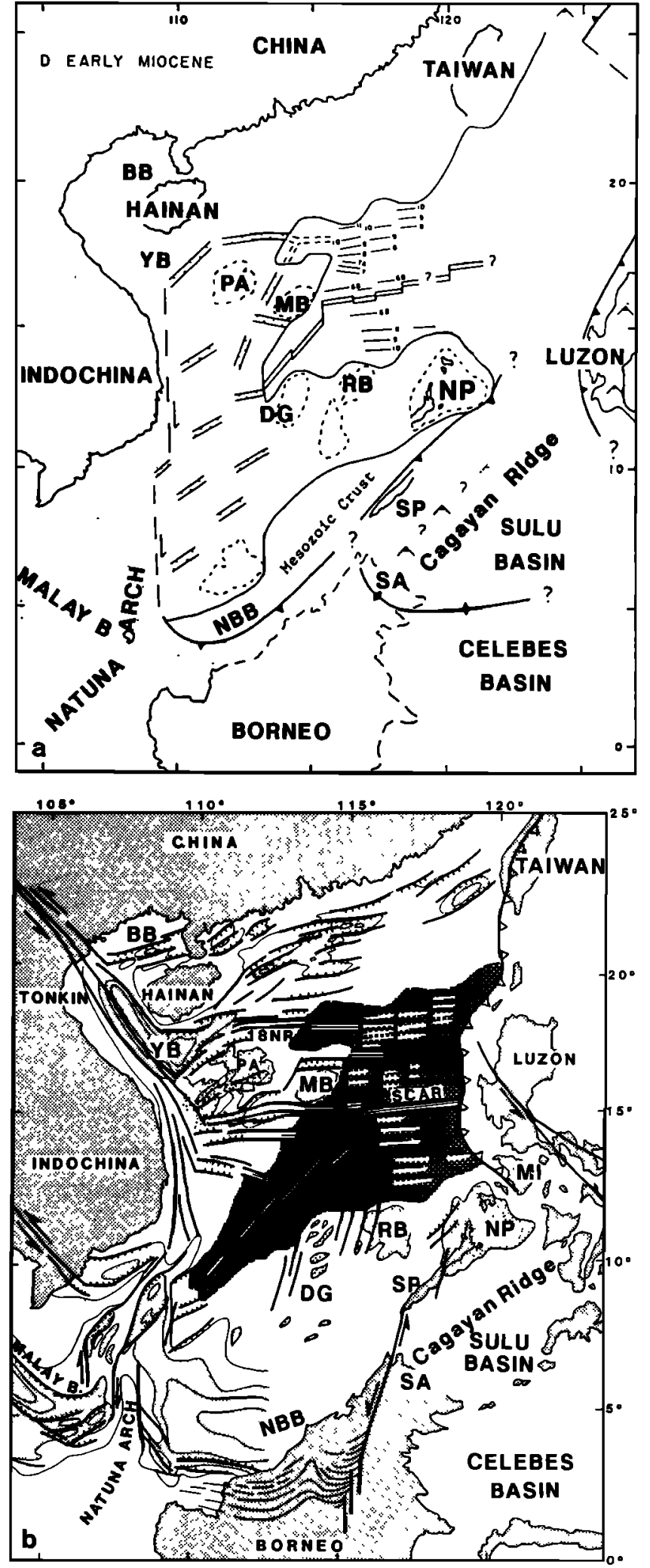

Fig. 13. Fundamental difference between previous models for the opening of the South China Sea. (a) Taylor and Hayes [1983] (Early-Miocene stage): Right-lateral faulting along the Vietnam transform, with Indochina and Borneo fixed relative to South China, (b) Tapponnier et al. [1986]: leftlateral faulting between South China and Indochina, with Borneo moving with Indochina. BB: Beibu Basin, DG: Dangerous Grounds (Spratly Islands), MB: Macclesfield Bank, NBB: North Borneo Basin, NP: North Palawan Block, PA: Paracels (Xisha) Islands, RB: Reed Bank, SA: Sabah, SCAR: Scarborough Seamount chain, SP: South Palawan Block, XT: Xisha Trough, YB: Yinggehai Basin. 
gated along that margin into the rift system (Figure 13b) [Tapponnier et al., 1982; Peltzer and Tapponnier, 1988]. The second process is now observed at the appropriate scale but at a more incipient stage in North China (Figure 15) [e.g., Tapponnier and Molnar, 1977]. These two hypotheses drastically oppose the two types of kinematic models of opening that have been put forward and represent two mechanisms that involve distinct driving forces. In the first type of model, the opening of the South China Basin is only driven by the inferred subduction of older oceanic crust into the North Borneo trough to the south. In the second type of model, the continental rifts first develop at the tip of propagating left-lateral strike-slip faults, and the extension is driven by the relative motion of Indochina, or of slices of it, that are pushed towards the SE or SSE relative to South China by the penetration of India into Asia. Subduction zones around the southeastern edge of Indochina mostly contribute to make that motion possible.

To our knowledge, work in regions south of the South China Sea has not yielded compelling evidence for hundreds of kilometers of shortening, consistent with subduction, followed by collision, during the period between 30 and $15 \mathrm{Ma}$. On seismic reflection profiles, the faulted Oligocene-Early Miocene carbonate platform that includes Dangerous Grounds, Reed Bank and underlies the North Palawan trough, apparently extends under South Palawan to the NW Sulu basin with a southward dip of only a few degrees [Hinz et al., 1985; Rangin and Silver, 1991]. This implies that the North Palawan trough merely results from elastic downwarping in response to loading by a thrust wedge along the NW edge of Palawan [Hinz and Schlüter, 1985; Hinz et al., 1985]. That thrust wedge may extend eastwards to Mindoro, where Mid-Oligocene oceanic crust, perhaps formely part of the South China seafloor, was obducted around $15 \mathrm{Ma}$ [Rangin et al., 1985]. Thus while up to a few tens of kilometers of shortening along the northwestern edges of Palawan [Rangin and Silver, 1991] and NE Borneo, particularly after the Mid-Miocene, have been documented, the existence of a subduction zone along the NW edge of Borneo and Palawan [Hamilton, 1979; Taylor and Hayes, 1980, 1983] is in doubt. The existence of many hundreds of kilometers of left-lateral movement along the Red River Fault in the Oligo-Miocene, on the other hand, is now corroborated by structural and paleomagnetic evidence, and by radiometric dating. For this reason, we shall focus on testing the second type of model, using the results of the reconstruction presented earlier in the paper.

The similarity between the large-scale pattern of fault zones in southeastern Asia and in indentation experiments suggests that the localization of strain along a small number of long and narrow strike-slip shear zones that propagate rapidly within the continental lithosphere is an inescapable element of continental tectonics [e.g., Tapponnier et al., 1986; Peltzer and Tapponnier, 1988; Davy and Cobbold, 1988; Peltzer, 1988]. To a first approximation, the various blocks bounded by these zones (Malaysia, Indochina, South China and North China) may thus be seen to behave as rigid rotating blocks, the motion of which may be described by plate tectonic parameters. We examine the mechanics of opening of the South China Sea in this light.

\section{Timing and Amount of Movement on Left-Lateral Southeast Asian Fault Zones}

The kinematics and ages of the deformation observed along the Red River Fault zone confirm that this zone has been a major midTertiary left-lateral boundary between South China and Indochina. Recent field work in Yunnan has revealed ubiquitous left-lateral ductile shear along the 1000-km-long Red River Fault zone. That shear has formed a 10-to-20-km-wide belt of high-grade gneisses, with near vertical foliation and near horizontal lineation [Tapponnier et al., 1990a; Leloup, 1991]. The shear zone includes leucogranites derived from late tectonic, anatectic melting within the gneisses, which probably imply shearing of the lithospheric mantle as well as the crust [Fleitout and Froidevaux, 1980]. Radiometric dating of leucogranites in two locations along the belt (Ailao Shan) yields an age of $23.0 \pm 0.2 \mathrm{Ma}$ for the late ductile deformation along the shear zone [Schärer et al., 1990]. Major uplift of the central Ailao Shan gneisses had occurred by $18 \mathrm{Ma}$ [Harrison et al., 1992]. The present offset between the Uttaraditt and the Jinsha sutures suggests that the amount of pre middle Miocene displacement along the fault has been at least 500-700 km [Tapponnier et al., 1986, 1990a; Peltzer and Tapponnier, 1988; Leloup, 1991]. From comparisons of the paleolatitudes of coeval red beds in Thailand and China, $Z$. Yang and J. Besse (Paleomagnetic study of Permian and Mesozoic sediments from Northern Thailand supports the extrusion model for Indochina, submitted to Earth and Planetary Science Letters, 1992, hereinafter referred to as Yang and Besse (submitted paper)) suggest as much as $1500 \pm 800 \mathrm{~km}$ of post middle Cretaceous displacement between the Indochina block and the South China block.

The Wang Chao and Three Pagodas Faults, that slice through Burma, Thailand and Cambodia, left-laterally offset the Early Mesozoic granite batholith of central Thailand by about $300 \mathrm{~km}$ [Tapponnier et al., 1986]. These faults also displace and deform Jurassic and Cretaceous rocks [Department of Mineral Resources, 1982], an observation which is compatible with Cenozoic movement on them. In the field, they show left-lateral shear in lowgrade mylonites and ultramylonites [Lacassin et al., 1992]. Paleomagnetic evidence suggests a $10-25^{\circ}$ clockwise rotation of the Khorat plateau, the stable core of Indochina, relative to Eurasia [Achache et al., 1983; Chen and Courtillot, 1989; Yang and Besse, submitted paper]. Finally, both the Red River and the Wang Chao faults have changed sense from left-lateral in Oligo-Miocene time to right-lateral in the Quaternary [Allen et al., 1984; Tapponnier et al., 1986], which has probably reduced the present-day left-lateral offsets of geological markers across them.

\section{Compatibility of Seafloor Spreading with Left Lateral Motion Along the Red River Zone}

Assuming that the regions north or south of the South China Sea ridge did not deform much between 32 and $16 \mathrm{Ma}$, and that blocks on the southern side of the South China Sea spreading ridge (Dangerous Grounds, Reed Bank and much of Borneo) remained attached to Indochina during the opening of the sea, the displacement on the Red River Fault estimated from reconstruction of the magnetic isochrons in the South China Sea is compatible with the sinistral shear recently documented in Yunnan (Figure 14). This positive test of kinematic compatibility is illustrated by moving back the northeastern boundary of Indochina, taken to lie along the present trace of the Red River Fault, relative to South China, using the rotation parameters derived from the study of the oceanic part of the basin (Tables 2, 3, Figure 12). Overall, the successive positions of the trace suggest that much of the spreading of the South China Sea may be related to strike-slip movement on that fault (Figure 14). Table 5 shows the direction, rate and amount of finite motion of two points (C, north of the Uttaraditt suture; $D$, near the Gulf of Tonkin) which now belong to the fault trace, computed from the stage poles of rotation derived from the magnetic isochrons (Table 3). The computed directions and the 
reconstruction of Figure 14 show that to first order the Red River Fault behaved as a transcurrent plate boundary, allowing Indochina and the blocks attached to it (Borneo, Dangerous Grounds, Reed Bank) to move southeast relative to South China. After $30 \mathrm{Ma}$, the
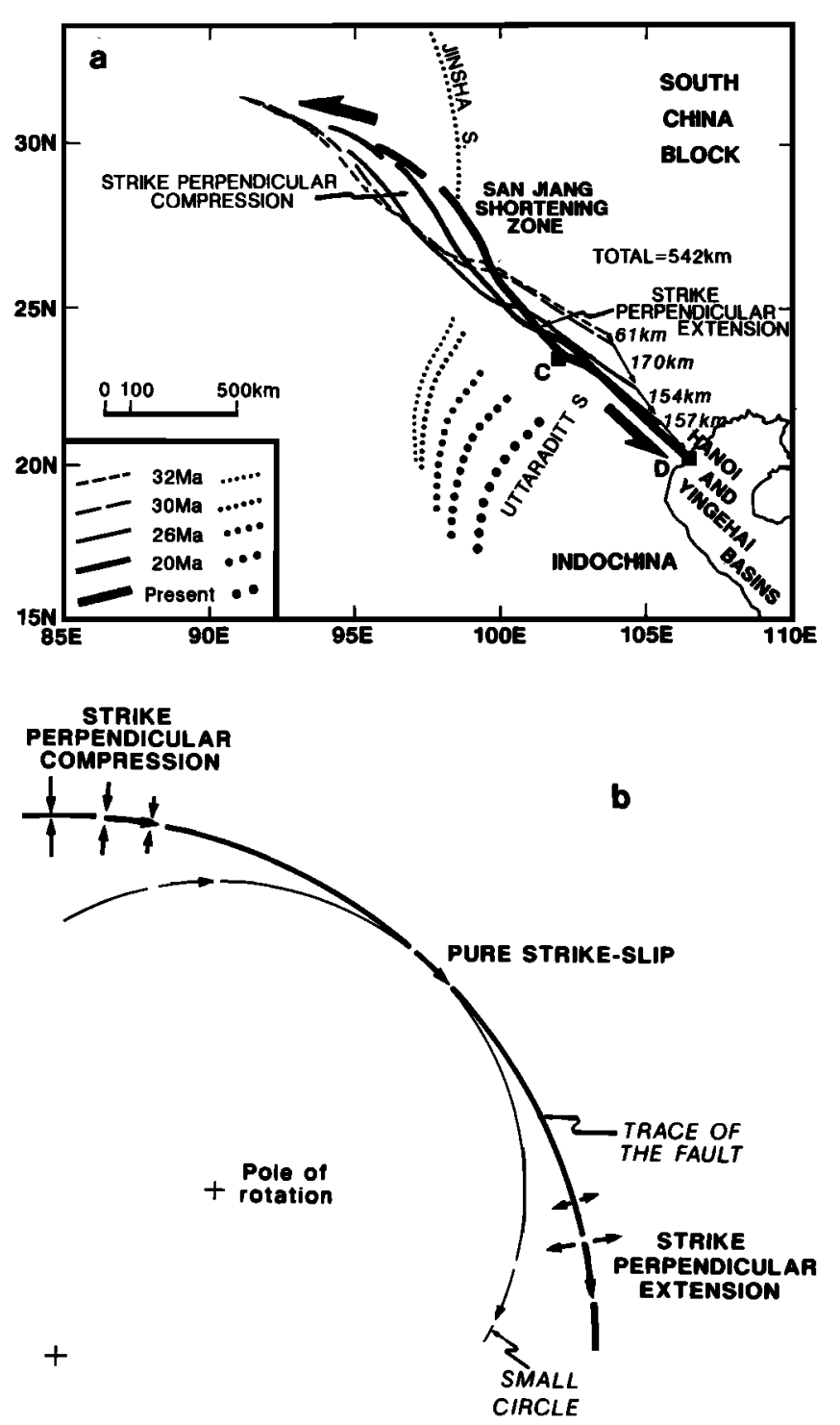

estimated left-lateral slip rate on the Red River Fault zone was of the order of $35 \mathrm{~mm} / \mathrm{yr}$, a value typical of great strike-slip faults at present. The total amount of left-lateral motion linked with seafloor spreading $(\sim 560 \mathrm{~km}$ ) (Figure 14, Table 5) is compatible with that estimated from the offset of the Jinsha-Uttaraditt suture [Peltzer and Tapponnier, 1988], which is seen to be nearly restored in Figure 14.

At a more detailed level, the reconstruction predicts that strikeperpendicular shortening $(\sim 160 \mathrm{~km})$ should have characterized the tectonics of regions along the northwestern segment of the fault in the San Jiang region, while strike-perpendicular extension $(\sim 130 \mathrm{~km})$ should have occurred along the southeastern segment of the fault (Figure 14, Table 5). These predictions are compatible with the observed shortening, by NNW-SSE trending folds, of the Mesozoic red beds in northwestern Yunnan [Tapponnier et al., 1990a], and with the apparent scissor opening of the wedge-shaped NW-SE Hanoi and Yinggehai basins. Such inferences, however, can only be taken as qualitative, since it is likely that late Miocene to present strain in Yunnan province, such as left-lateral motion along the N-S trending Xiaojang Fault and continuing dextral shear in the China-Burma border region, has bent the trace of the Red River Fault, whose western segment is now concave to the north. Nevertheless, the strike-perpendicular compression and extension during Tertiary left-lateral shear probably reflect the fact that the fault was not a small circle about the Indochina/South China average pole of rotation $\left(5.3^{\circ} \mathrm{N}, 66.3^{\circ} \mathrm{E}\right.$, Figure $\left.12 \mathrm{a}\right)$, this pole being closer to the trace of the fault than if this had been the case (Figure 14b). Other large active strike-slip faults of Asia (in particular the Altyn Tagh-Haiyuan fault system) also slice across regions of shortening in the west (Tibet) and regions of extension in the east (Shansi and North China plains) (Figure 15) [e.g., Tapponnier et al., 1986; Peltzer and Tapponnier, 1988].

Fig. 14. (a) Successive positions (relative to South China) of northern boundary of Indochina (taken to lie along the present-day trace of the Red River Fault ), moved back at times of anomalies 6,7 (ridge jump), 10 and 11 , using the poles of rotation listed in Table 1 . Blocks south of the spreading ridge are assumed to have been part of the Sunda shelf since 32 Ma. (b) Strike-perpendicular compression and extension resulting from a smaller distance between the pole of rotation and the fault than if the fault were a small circle.

TABLE 5. Directions (D), Rates and Amounts of Displacement on Two Points of Red River Fault

\begin{tabular}{|c|c|c|c|c|c|c|c|c|c|}
\hline \multirow[b]{2}{*}{ Anomalies } & \multirow[b]{2}{*}{$\begin{array}{c}\text { Age end, } \\
\text { Ma }\end{array}$} & \multicolumn{4}{|c|}{$\begin{array}{c}\text { Point C } \\
\text { (Near Northern End } \\
\text { of Uttaraditt Suture) }\end{array}$} & \multicolumn{4}{|c|}{$\begin{array}{c}\text { Point D } \\
\text { (Near Immersion } \\
\text { in Gulf of Tonkin) }\end{array}$} \\
\hline & & $\begin{array}{l}\Delta, \\
\operatorname{deg}\end{array}$ & $\begin{array}{l}\mathrm{D}, \\
\text { deg }\end{array}$ & $\begin{array}{l}\text { Rate, } \\
\mathrm{mm} / \mathrm{yr}\end{array}$ & $\begin{array}{c}\text { Finite } \\
\text { Displ., km }\end{array}$ & $\begin{array}{l}\Delta, \\
\text { deg }\end{array}$ & $\begin{array}{c}D \\
\text { deg }\end{array}$ & $\begin{array}{l}\text { Rate, } \\
\mathrm{mm} / \mathrm{yr}\end{array}$ & $\begin{array}{c}\text { Finite } \\
\text { Displ., km }\end{array}$ \\
\hline End $-5 e$ & 15.64 & 28 & -59 & 37 & 124 & 28 & -49 & 37 & 124 \\
\hline $5 e-6$ & 19.00 & 46 & -12 & 30 & 43 & 49 & -8 & 31 & 45 \\
\hline $6-$ jump & 20.45 & 18 & -40 & 27 & 147 & 19 & -26 & 28 & 154 \\
\hline jump -8 & 25.91 & 9 & -69 & 29 & 57 & 8 & -38 & 27 & 51 \\
\hline $8-10$ & 27.74 & 78 & -9 & 50 & 128 & 82 & -7 & 50 & 130 \\
\hline $\begin{array}{l}10-11 \\
\text { Total }\end{array}$ & 30.32 & 21 & -32 & 62 & $\begin{array}{r}56 \\
\mathbf{5 5 5}\end{array}$ & 23 & -21 & 66 & $\begin{array}{r}61 \\
565\end{array}$ \\
\hline End - 6 & 15.64 & 30 & -50 & 33 & 157 & 30 & -39 & 33 & 157 \\
\hline jump - 10 & 25.91 & 22 & -27 & 37 & 157 & 24 & -17 & 39 & 170 \\
\hline
\end{tabular}

Directions and amounts computed from stage poles obtained with Patriat's [1987] method. Points C and D shown in Figure 14. D taken positive eastward. Symbol $\Delta$, distance between stage pole of rotation and point of measurement. 


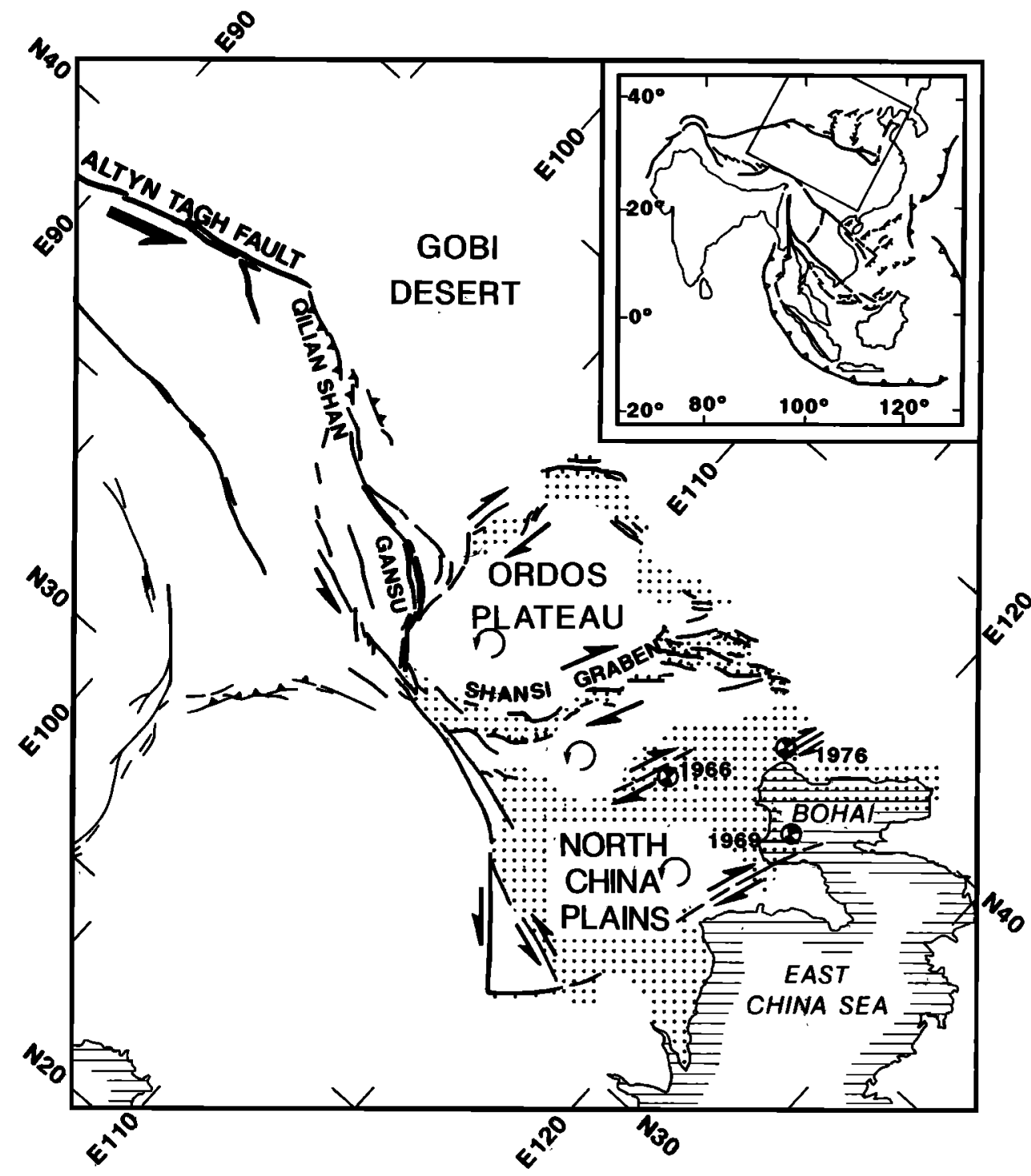

Fig. 15. Present-day tectonics of Altyn Tagh-Haiyuan-Qinling left-lateral fault system with associated zones of compression, and en échelon rifts and right-lateral faults in North China. Adapled from Tapponnier and Molnar [1977]. Fault plane solutions of the 1966 Xing Tai, 1969 Bohai, and 1976 Chan Tang earthquakes are shown. Inferred counterclockwise rotation of blocks is after Peltzer and Tapponnier [1988]. This may be viewed as the incipient analog of the Red River Fault system during the Oligocene.

\section{Relationship Between the Opening of the South China Basin and Surrounding Continental Strike-Slip Tectonics}

The following palinspastic scenario rests upon the compatibility, outlined above, between the parameters of spreading in the South China Sea and the kinematics of faulting in Southeast Asia, which suggests that the assumptions made are plausible. It also takes into account other geological constraints summarized by Hamilton [1979], Holloway [1982], Taylor and Hayes [1983], Tapponnier et al. [1986] and Rangin and Silver [1991]. We begin with a hypothetical reconstruction of Southeast Asia shortly after the onset of rifting in the South China Sea and on the Sunda shelf (Figure 16a). We then present a series of palinspastic maps (Figures 16b-16e), in which the successive rotations of Southeast Asian blocks, and of observed structural markers fixed to them, are computed only from the fit of magnetic isochrons identified in the South China Sea. The final map (Figure 16f) shows the tectonic changes that have occurred near the southeastern margin of the basin between the end of spreading and the present time.
First stages of rifting - Eocene to Mid-Oligocene ( 40 to $30 \mathrm{Ma}$ ). The beginning of the rifting is dated as Eocene to early Oligocene by subsidence studies along the South China margin [Holloway, 1982; Ru and Pigott, 1986; Su et al., 1989] and as latest Cretaceous-Eocene by seismic and well studies on the southern Sunda shelf [Hinz and Schlüter, 1985; Hinz et al., 1985; Rangin and Silver; 1991]. Because the Thai, Malay and north Borneo (Zengmu) basins, with up to $10 \mathrm{~km}$ of sediments [Anderson et al., 1978] lie along the extension of the Three Pagodas and associated strike-slip faults, we take the view that rifting within the Sunda shelf was related to left-lateral motion along this fault system [e.g. Zhang Wen You, 1983; Tapponnier et al., 1986] (Figure 16a). As a result of such left-lateral motion, it is possible that oceanic crust formed in the late Eocene in the easternmost part of the extensional system (Figure 16), yielding a source for the obducted ophiolites of Central Palawan (H. Kreuser, unpublished report, 1983, as cited in the work by Hinz et al. [1985]), and the Cagayan volcanics [Rangin and Silver, 1991]. 

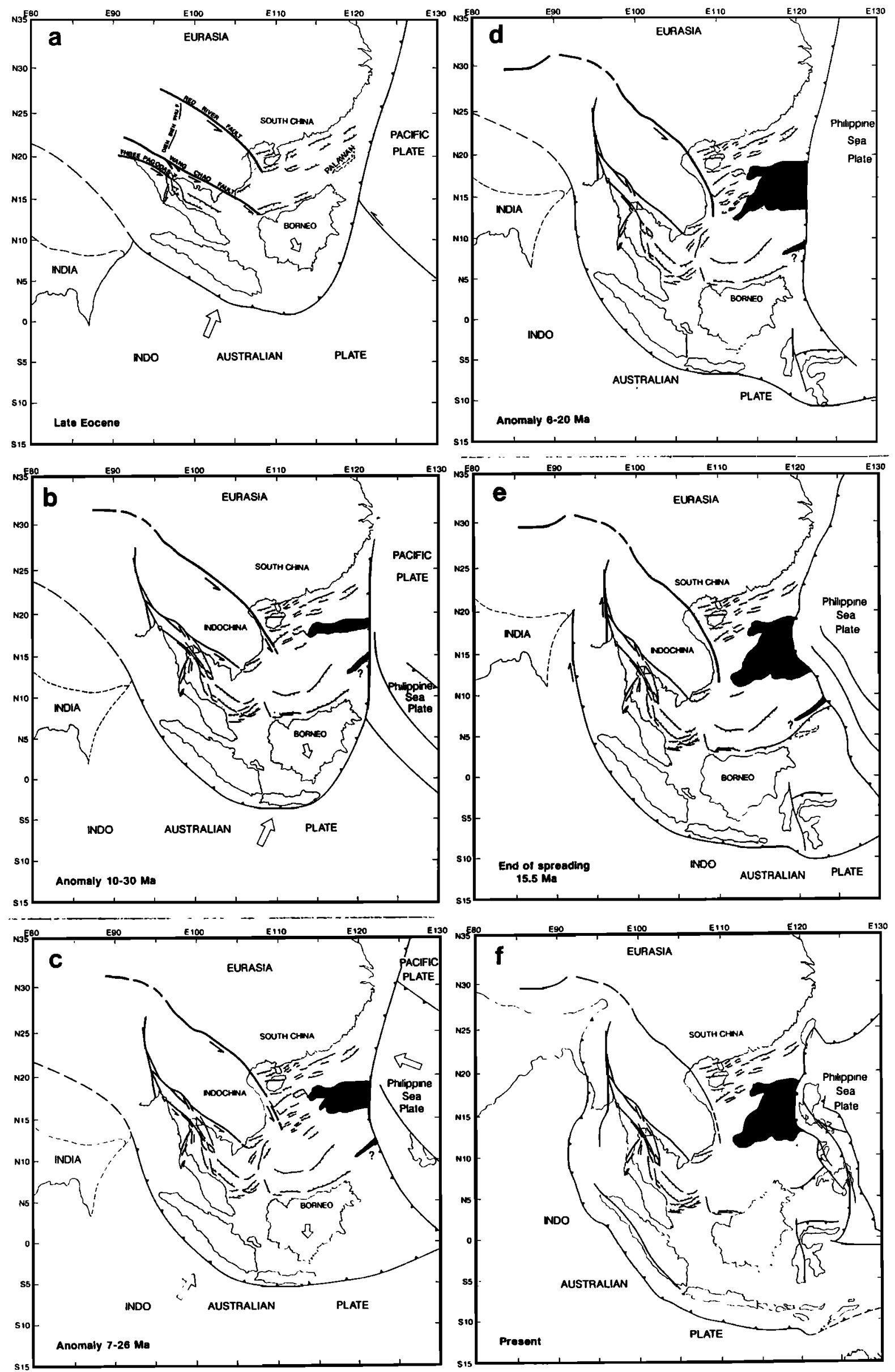
First stage of spreading in the basin: Anomaly 11 (32 Ma). Seafloor spreading started to the north in a basin parallel to the South China margin (including the northwestern rift). That basin was probably part of a system of basins arranged en échelon, branching at the tip of the Red River Fault (Figure 16b). The Beibu (Gulf of Tonkin) and Yinggehai (west of Hainan Island) troughs formed pull-apart basins at the southern tip of the Red River Fault system [Zhang Wen You, 1983; Tapponnier et al., 1986]. Expanding spread profiles performed on the South China margin reveal that the crust beneath the Xisha trough (Figure 13) is anomalously thin, suggesting that this trough is also a failed rift [Hayes and Spangler, 1988].

Jumps and southeastward propagation of spreading: A result of southward propagation of the Red River Fault. At the time of anomaly 10 (30 Ma) spreading stopped in the northwestern rift, but continued east of Macclesfield Bank (Figure 16b). Free air gravity anomalies [B. Chen, 1987] suggest that the western part of Macclesfield Bank was affected by rifting, while the eastern half behaved as a single block. That extension in the South China Basin was more diffuse in the west than in the east has long been recognized [Taylor and Hayes, 1980, 1983; Hayes, 1985]. We interpret this as a result of the propagation of the Red River Fault tip to the south, leading to transient, diffuse stretching and rifting, which never evolve into stable seafloor spreading because of their proximity to the fault tip. This process may have been dominant in the area west of Macclesfield Bank (Figures 16c, 16d and 17).
Just after anomaly 7 the spreading system jumped to the south, and the ridge began to propagate towards the southwest (Figures 10 and 16d). We infer that a preexisting crustal fabric or the rheology of the lithosphere prevented the ridge from jumping and propagating in a single step, at the time of anomaly 10 , and maintained Macclesfield and Reed Banks together between anomalies 10 and $6 b$ (Figures 16b, 16c and 16d). With $=500 \mathrm{~km}$ of propagation between anomaly $7(26 \mathrm{Ma})$ and the cessation of spreading $(16 \mathrm{Ma})$, the rate of southwestward propagation of the rift was $50 \mathrm{~mm} / \mathrm{yr}$ on average. It might have been as fast as $83 \mathrm{~mm} / \mathrm{yr}$ if most of the propagation occurred before anomaly 6 (20 Ma). Relatively rapid propagation $(30 \mathrm{~mm} / \mathrm{yr})$ and localization of a spreading center into diffusely rifted and stretched continental crust is observed at present in southern Afar along the Gulf of Tadjourah [Courtillot, 1982; Courtillot et al., 1984]. The Afar area is characterized by rotations of blocks of various scales [e.g., Tapponnier et al., 1990b; Acton et al., 1991] at relatively fast rates $\left(1 \% 10^{5}\right.$ years $)$, in a region where "buffer" zones of diffuse extension coexist with more localized, overlapping volcanic rifts. In the South China Sea, the zone west of and between Macclesfield and Reed Banks may have represented such a transition region into which the spreading center only localized and propagated from anomaly 7 onwards. At present, there is no information on possible tectonic rotations at the scale of blocks such as Macclesfield Bank. Our interpretation predicts counterclockwise rotations (Figure 17), comparable to those now inferred in
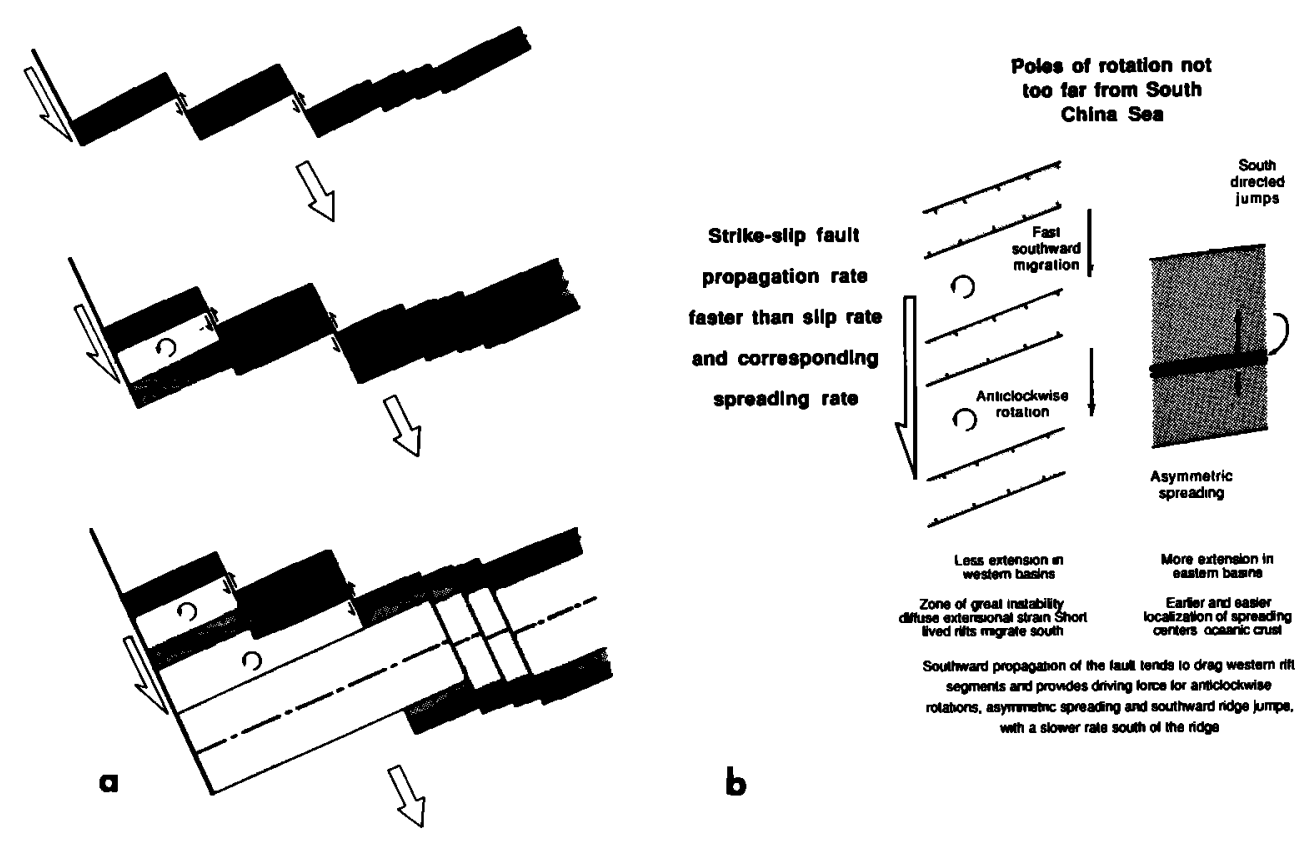

Fig. 17. (a) Sketch showing how strike-slip fault propagation may lead to transient extension near the fault while more steady spreading occurs farther away. (b) Sketch showing how left-lateral strike-slip fault propagation might account for complexities in the opening of the South China Sea.

Fig. 16. (a) Hypothetical reconstruction of the first stage of extension of the Sunda shelf. Formation of north Borneo extensional trough. (b) to (e) Reconstruction of South China Sea and Southeast Asia at times of anomalies 10 (30 Ma), 7 (26 Ma), 6 (20 Ma), and when spreading stopped (15.5 Ma). (f) Present-day geometry of South China Sea and surrounding regions of Southeast Asia. Note the rotation of Borneo between $16 \mathrm{Ma}$ and present. Speckled areas are stretched continental crust; dark areas, oceanic crust. 
Northeast China (Figure 15) [Peltzer and Tapponnier, 1988], while interpretations involving right-lateral shear along Vietnam [Holloway, 1982; Taylor and Hayes, 1983] predict clockwise rotations. Hence paleomagnetic studies of oriented cores might allow to test for such rotations and decide which interpretation is more likely. We note that Tertiary counterclockwise rotations have been documented along the fragmented northwestern edge of Borneo [Schmidtke et al., 1990], east of the extremity of the leftlateral Wang Chao-Three Pagodas fault system, a region probably analogous to those discussed above.

The directions of spreading computed from the finite poles of rotation are closer to NNW-SSE after the ridge jump (26 Ma). This leads to the reorientation of the spreading segments from E-W to $\mathrm{N} 70^{\circ} \mathrm{E}$ observed in the east (Figure 11), with anomalies more recent than anomaly $6 \mathrm{~b}$ all displaying a very disrupted pattern, while spreading segments in the southwest, which are relatively long, probably formed roughly perpendicular to the spreading direction as the ridge system propagated to the southwest. Within a large-scale tectonic framework dominated by left-lateral motion between Indochina and South China, the jumps, the readjustments in spreading direction, and the irregular southwestward propagation of the spreading center may be viewed as a consequence of the southsoutheastward propagation of the Red River Fault. From a position southwest of Hainan $\left(17^{\circ} \mathrm{N}\right.$ in a reference frame fixed to presentday South China) around $30 \mathrm{Ma}$, the Red River Fault tip might have propagated to a position southeast of Vietnam $\left(11^{\circ} \mathrm{N}\right.$ in that same reference frame) around $20 \mathrm{Ma}$, or about $600 \mathrm{~km}$ in $10 \mathrm{Ma}$, at an average rate of $60 \mathrm{~mm} / \mathrm{yr}$. That both the average rate of slip on the Red River Fault and of opening in the South China Sea (35$50 \mathrm{~mm} / \mathrm{yr}$ ) are less than the average rate of propagation of the tip of that fault is to be expected. If only elastic stresses governed the propagation of large-scale tensile or shear discontinuities in the lithosphere, a much faster rate of propagation than of slip or opening, in proportion to the aspect ratio of such discontinuities, would ensue. Even with viscous strain in the more ductile layers of the lithosphere damping propagation, it seems likely that the rate of propagation would remain greater that the rate of slip on the fault.

The propagation of the spreading system stops at anomaly 6 (20 Ma) (Figures 11, 16d, and 16e). It is possible that at this time a steady state connection was finally reached between the Red River strike-slip fault and the South China Sea spreading center, although that connection is difficult to trace with extant data. The estimated motion on the fault is then almost purely strike slip, as seen in Figure 14. The strike-slip fault is closest to a transform fault, its horizontal motion being transmitted almost entirely to the spreading system. This scenario might explain the increase in the spreading rate after anomaly $5 \mathrm{~d}$. The homogeneous NE-SW orientation of scarps, visible on the Sea Beam bathymetry [Pautot et al., 1986, 1990; Briais et al., 1989], suggests that this situation and the $\mathrm{N} 140 \pm 10^{\circ} \mathrm{E}$ spreading direction remained steady until the cessation of the spreading.

Cessation of spreading. After $16 \mathrm{Ma}$, spreading apparently stopped all along the ridge axis (Figures 11 and 16e). In the interpretation discussed here, the end of spreading is seen as a consequence of processes occurring well beyond the margins of the South China Sea. We suggest it is related to the cessation of motion on the Red River Fault, itself inferred to result from the deformation and clockwise rotation of the fault system, and to changes in the stress field as the Indian indenter passes Malaysia and Indochina [e.g., Tapponnier et al., 1986; Peltzer and Tapponnier, 1988]. The middle Miocene is also a time of crustal shortening between Palawan and the Cagayan Ridge to the south
[Rangin and Silver, 1991]. This deformation probably attests to more efficient coupling between the Philippine and the Eurasian Plates. Similarly, more active terrane accretion, leading to the present-day collision with Australia, begins along the Eastern Sunda subduction zones. Both factors may have contributed to stop the southeastward extrusion of Indochina (Figure 16f).

\section{CONCLUSION}

Clearly, the reconstructions presented here, the choice of hypotheses from which they derive and the palinspastic scenarios with which they are compatible are not unique. One particularly important hypothesis is the choice of the magnetic anomaly sequence in the southwestern basin. Nevertheless, because the Red RiverAilaoshan fault zone is a large Oligo-Miocene discontinuity that extends into the South China Sea, with apparently at least 500 to $600 \mathrm{~km}$ of left-lateral displacement, and because displacement on this fault is compatible with seafloor spreading in that sea, we believe that it has played a leading role in the formation and evolution of the sea. The reconstructions of Figure 16 are the simplest that account for the existing body of observations both within the basin and in continental regions surrounding it to the north and west.

At a more detailed level, the inference that the opening of the South China Sea basins is linked with the propagation of a large left-lateral strike-slip fault (the Red River Fault) along their western margin, and the average position, relative to this fault, of the Indochina/South China rotation poles, provide kinematically and mechanically acceptable ways to account for the complex shape of the basins, the transition between seafloor spreading in the east and diffuse extension in the west, possible counterclockwise rotations in zones of diffuse extension, as well as generally asymmetric spreading and systematically south-directed ridge jumps. This is schematically summarized in Figures $17 \mathrm{a}$ and $17 \mathrm{~b}$. That the stage poles of rotation are roughly aligned on a great circle that crosses the South China Sea suggests that the mechanism of opening did not change drastically during the opening (Figure 12).

At the core of the extrusion scenarios proposed by Peltzer et al. [1982] and Tapponnier et al. $[1982,1986]$ is the hypothesis that the collision between India and Asia provides an essential part of the forces driving seafloor spreading in the South China Sea, and that subduction alone, south and east of that sea, although required to allow extrusion, would not suffice to do the job. The work presented here supports this inference. Collision has probably contributed to guide the kinematics of seafloor spreading in the South China Sea in two ways. First, it has activated large, concave to the south, left-lateral strike-slip faults cutting eastern Asia and terminating into pull-aparts. Second, as India penetrated north into Asia, thus moving past Indochina, it probably induced successive, clockwise rotations of the large blocks extruded between these faults. The faults are thus less curved than the small circles about the Euler poles deduced from seafloor spreading reconstruction (Figure 14). Our results suggest that the geometry, kinematics, displacement fields and scale dependence of the faulting pattern and of the block rotations are best illustrated by the quantitative descriptions of the plasticine experiments that were first used to model extrusion tectonics in Asia [Peltzer, 1983; Peltzer and Tapponnier, 1988], even though such experiments are on a plane, and not, as on Earth, a spherical surface.

Although paleomagnetic studies have revealed counterclockwise rotations of Mesozoic and Cenozoic rocks along the deformed southern margin of the South China Sea [Schmidtke et al., 1990], the clockwise rotation of the Khorat red beds, which rest upon the 
relatively undeformed core of Indochina, attests to a $10^{\circ}$ to $25^{\circ}$ clockwise bulk rotation of Indochina relative to Asia [Achache et al., 1983; Chen and Courtillot, 1989; Yang and Besse, submitted paper]. This rotation is in keeping with the reconstruction presented here, where seafloor spreading alone induces about $12^{\circ}$ of clockwise rotation of Indochina relative to South China. The existence of a relative rotation between these two large continental blocks draws attention to a radical shortcoming of the plane-strain, large-scale "domino" models that are now in fashion to describe strike-slip deformation in collision zones [e.g., Dewey et al., 1989; England and Molnar, 1990]. Although the parallel strike-slip faults that separate the adjacent, "domino"-shaped blocks in such models lead to fast, coeval rotation of the blocks, they permit no rotation of one block relative to the next. Both the analysis of magnetic isochrons in the South China Sea, and the paleomagnetic declinations observed in the late Mesozoic beds of the Khorat thus imply that plane strain, "domino" models provide incorrect descriptions of the Cenozoic tectonics of Southeast Asia. As convergence between India and Asia was progressively absorbed north of what is now the Ganges plain, it is unlikely that blocks located far north of India rotated as fast as those located closer to it. It is also unlikely that they started to rotate at the same time and rotated the same amount. Recent studies [Chen et al., 1991; Meyer, 1991; Avouac et al., 1992] suggest in fact that the finite Cenozoic clockwise rotations of the Tarim and of the Qaidam are only of the order of $8^{\circ}$ and $6^{\circ}$, respectively, while parts of western Sichuan and Yunnan may have rotated by $40^{\circ}$ or more [Otofuji et al., 1990; Huang et al., 1992]. It is no surprise that in the 50-m.y.-long collision history, Indochina was the first large Asian block to rotate clockwise and that it rotated relative to South China while moving hundreds of kilometers to the SE-SSE [Peltzer and Tapponnier, 1988]. A time-dependent, northward decrease of the clockwise rotation of blocks separated by dominantly strike-slip faults makes extrusion an inescapable component of the large-scale deformation of the zone lying east of India throughout the collision, the rate and amount of rotation of each block merely affecting the direction in which it escapes.

Acknowledgments. Particular thanks are due to Dennis Hayes for inviting A.B. to participate to Conrad cruises RC2613 and RC2614 and to spend 4 months at the Lamont-Doherty Geological Observatory, and for allowing her to use unpublished data from these cruises in her Ph.D. thesis. These data helped us interpret the Chinese data presented here. Jean-Yves Royer kindly provided us with his programs to fit magnetic isochrons. We have greatly benefitted from discussions with Rolando Armijo, Jean Besse, Robin Lacassin, Hervé Leloup, Bertrand Meyer, and Gilles Peltzer. We also appreciated Kurt Feigl's critical reading and Guy Aveline's technical support. Remarks from Brian Taylor and an anonymous reviewer helped improve the final version of the paper. This is IPGP contribution 1240.

\section{REFERENCES}

Achache, J., V. Courtillot, and J. Besse, Paleomagnetic constraints on the late Cretaceous and Cenozoic tectonics of southeastern Asia, Earth Planet. Sci. Lett., 63, 123-136, 1983.

Acton, G., S. Stein, and J. F. Engeln, Block rotation and continental extension in Afar: A comparison to oceanic microplate systems, Tectonics, 10, 501-526, 1991.

Allen, C. R., A. R. Gillespie, Y. Han, K. E. Sieh, B. Zhang, and C. Zhu, Red River and associated faults, Yunnan province, China: Quaternary geology, slip rates, and seismic hazard, Geol. Soc. Am. Bull., 95, 686700, 1984.

Anderson, R. N., 1980 update of heat flow in the East and Southeast Asian seas, in The Tectonic and Geologic Evolution of Southeast Asian Seas and Islands, Part 1, Geophys. Monogr. Ser., vol. 23, edited by D. E. Hayes, pp. 318-326, AGU, Washington, D. C., 1980.

Anderson, R. N., M. G. Langseth, D. E. Hayes, T. Watanabe, and M.
Yashui, Heat flow, thermal conductivity, thermal gradient, in Geophysical Atlas of East and Southeast Asian Seas, Map and Charts Ser., vol. MC 25 , edited by D. E. Hayes, Geological Society of America, Boulder, Colo., 1978.

Avouac, J.-P., P. Tapponnier, and G. Peltzer, Active thrusting and folding along the northeastern Tien Shan, and Late Cenozoic rotation of the Tarim relative to Dzungaria and Kazakhstan, J. Geophys. Res., in press, 1992.

Berggren, W. A., D. V. Kent, J. J. Flynn, and J. A. Van Couvering, Cenozoic geochronology, Geol. Soc. Am. Bull., 96, 1407-1418, 1985.

Blakely, R., and A. Cox, Identification of short polarity events by transforming marine magnetic profiles to the pole, J. Geophys. Res., 77, 4339-4349, 1972.

Bowin, C., R. S. Lu, C. Lee, and H. Schouten, Plate convergence and accretion in the Taiwan-Luzon region, Am. Assoc. Pet. Geol. Bull., 62, 1645-1672, 1978 .

Briais, A., P. Tapponnier, and G. Pautot, Constraints of Seabeam data on crustal fabrics and seafloor spreading in the South China Sea, Earth Planet. Sci. Lett., 95, 307-320, 1989.

Chang, T., On the statistical properties of estimated rotations, J. Geophys. Res., 92, 46319-46329, 1987.

Chen, B., Free air gravity anomalies, in Atlas of Geology and Geophysics of the South China Sea, scale 1:2,000,000, Second Mar. Geol. Invest. Brigade of the Minist. of Geol. and Miner. Resour., Guangdong Province, Guangdong, 1987.

Chen, S., Magnetic profiles, in Atlas of Geology and Geophysics of the South China Sea, scale 1:2,000,000, Second Mar. Geol. Invest. Brigade of the Minist. of Geol. and Miner. Resour., Guangdong Province, Guangdong, 1987.

Chen, Y., and V. Courtillot, Widespread Cenozoic (?) remagnetization in Thailand and its implications for the India-Asia collision, Earth Planet. Sci. Lett., 93, 113-122, 1989.

Chen, Y., J.-P. Cogné, V. Courtillot, J.-P. Avouac, P. Tapponnier, G. Wang, M. Bai, H. You, M. Li, C. Wei, and E. Buffeteau, Paleomagnetic study of Mesozoic continental sediments along the Northern Tien Shan (China) and heterogeneous strain in Central Asia, $J$. Geophys. Res., 96, 4065-4082, 1991.

Cochran, J. R., A model for development of Red Sea, Am. Assoc. Pet. Geol. Bull., 67, 41-69, 1983.

Courtillot, V., Opening of the Gulf of Aden and Afar by progressive tearing, Phys. Earth Planet. Inter., 21, 343-350, 1982.

Courtillot, V., J. Achache, F. Landre, N. Bonhommet, R. Montigny, and G. Féraud, Episodic spreading and rift propagation: New paleomagnetic and geochronologic data from the Afar nascent passive margin, $J$. Geophys. Res., 89, 3315-3333, 1984.

Davy, P., and P. Cobbold, Indentation tectonics in nature and experiments, 1, Experiments scaled for gravity, Bull. Geol. Instit. Univ. Uppsala, 14, 129-141, 1988.

Department of Mineral Resources, Geological Map of Thailand, scale 1:1,000,000, Royal Thai Surv. Dep., Bangkok, 1982.

Dewey, J. F., S. Cande, and W. C. Pitman III, Tectonic evolution of the India/Eurasia collision zone, Eclogae Geol. Helv., 82/3, 717-734, 1989.

Dixon, T. H., R. J. Stern, and I. M. Hussein, Control of Red Sea rift geometry by Precambrian structures, Tectonics, 6, 551-571, 1987.

England, P., and P. Molnar, Right-lateral shear and rotation as the explanation for strike-slip faulting in eastern Tibet, Nature, 344, 140 $142,1990$.

Fleitout, L., and C. Froidevaux, Thermal and mechanical evolution of shear zones, J. Struct. Geol., 2(1/2), 159-164, 1980.

Fricaut, L., Etude géologique et structurale de la marge nord-Palawan, Thèse de 3ème cycle, Univ. Paris XI, 1984.

Hamilton, W., Tectonics of the Indonesian Region, 345 pp., U.S. Government Printing Office, Washington, D. C., 1979.

Harrison, T. M., W. Chen, P. H. Leloup, F. J. Ryerson, and P. Tapponnier, Termination of left-lateral strike-slip motion along the Red River Fault, Ailao Shan, Yunnan, PRC, J. Geophys. Res., 97, 71597182, 1992.

Hayes, D. E., Margins of the southwest sub-basin of the South China Sea - A frontier exploration target ?, Energy, 10, 373-382, 1985.

Hayes, D. E., and S. E. Spangler, The South China Sea continental margin: Geophysical constraints on rifting (abstract), Eos Trans. AGU, $69,1413,1988$.

Hayes, D. E., and B. R. Taylor, Magnetic anomalies, in Geophysical Atlas of East and Southeast Asian Seas, Map and Charts Ser., vol. MC 25, 
edited by D. E. Hayes, Geological Society of America, Boulder, Colo., 1978.

Hayes, D. E., S. Spangler, W. Zeng, B. Yao, B. Taylor, and A. Briais, Age and evolution of the South China Sea southwest sub-basin (abstract), Eos Trans. AGU, 68, 1496, 1987.

Hékinian, R., P. Bonté, G. Pautot, D. Jacques, L. Labeyrie, N. Mikkelsen, and J.-L. Reyss, Volcanics from the South China Sea ridge system, Oceanol. Acta, 12, 101-115, 1989.

Hellinger, S. J., The uncertainties of finite rotations in plate tectonics, $J$. Geophys. Res., 86, 9312-9318, 1981.

Hey, R. N., A new class of pseudofaults and their bearing on plate tectonics: A propagating rift model, Earth Planet. Sci. Lett., 37, 321$325,1977$.

Hey, R. N., H. W. Menard, T. M. Atwater, and D. W. Caress, Changes in direction of seafloor spreading revisited, J. Geophys. Res., 93, 2803$2811,1988$.

Hinz, K., and H. U. Schlüter, Geology of the Dangerous Grounds, South China Sea, and the continental margin off Southwest Palawan: Results of Sonne cruises SO-23 and SO-27, Energy, 10, 282-288, 1985.

Hinz, K., E. H. K. Kempter, and H. U. Schlüter, The southern PalawanBalabac area: An accreted or non-accreted terrane ?, paper presented at the 3rd Asian Council on Petrol. (ASCOPE) Conf. and Exhib., Kuala Lumpur, Malaysia, 2-5 Dec., 1985.

Holloway, N. H., North Palawan Block, Philippines, Its relation to Asian mainland and role in evolution of the South China Sea, Am. Assoc. Pet. Geol. Bull., 66, 1355-1383, 1982.

Huang, K., N. D. Opdyke, X. Peng, and J. Li, Paleomagnetic results from the Upper Permian of the eastern Qiangtang Terrane of Tibet and their tectonic implications, Earth Planet. Sci. Lett., 111, 1-10, 1992.

Jolivet, L., P. Huchon, and C. Rangin, Paleogeodynamic reconstructions of Western Pacific, Tectonic setting of marginal basins, Tectonophysics, 160, 23-47, 1989.

LaBrecque, J., D. V. Kent, and S. C. Cande, Revised magnetic polarity time scale for Late Cretaceous and Cenozoic time, Geology, 5, 330-335, 1977.

Lacassin R., P. H. Leloup, and P. Tapponnier, Bounds on strain in large Tertiary shear zones of SE Asia from boudinage restoration, J. Struct. Geol., in press, 1992.

Leloup, P. H., Cinématique des déformations "Himalayennes" dans la zone de cisaillement de l'Ailao Shan - Fleuve Rouge, Thèse d'Univ., 308 pp., Univ. Paris 6, 1991.

Le Pichon, X., Résumé des cours et travaux, Annuaire du Collège de France 1987-1988, 135-144, Collège de France, Paris, 1988.

Lu, W., C. Ke, J. Wu, J. Liu, and C. Lin, Characteristics of magnetic lineations and tectonic evolution of the South China Sea basin, Acta Oceanol. Sin., 6, 577-588, 1987.

Menard, H. W., and T. M. Atwater, Changes in direction of sea floor spreading, Nature, 219, 463-467, 1968.

Meyer, B., Mécanismes des grands tremblements de terre et du raccourcissement crustal oblique au bord nord-est du Tibet, Thèse d'Univ., 314 pp., Univ. Paris 6, 1991.

Otofuji, Y., Y. Inoue, S. Funahara, F. Murata, and X. Zheng, Palaeomagnetic study of eastern Tibet - Deformation of the Three Rivers region, Geophys. J. Int., 103, 85-94, 1988.

Patriat, P., L'évolution du système de dorsales de l'Océan Indien, Terres Australes et Antartiques Françaises, 310 pp., Paris, 1987.

Pautot, G., C. Rangin, A. Briais, P. Tapponnier, P. Beuzart, G. Lericolais, X. Mathieu, J. Wu, S. Han, H. Li, Y. Lu, and J. Zhao, Spreading direction in the Central South China Sea, Nature, 321, 150$154,1986$.

Pautot, G., C. Rangin, A. Briais, J. Wu, S. Han, H. Li, Y. Lu, and J. Zhao, The axial ridge of the South China Sea: A Sea Beam and geophysical survey, Oceanol. Acta, 13, 129-143, 1990.

Peltzer, G., Naissance et évolution des décrochements lors d'une collision continentale, approche expérimentale, application à la tectonique de l'est de l'Asie, Thèse de 3ème cycle, 157 pp., Univ. Paris VII, 1983.

Peltzer, G., Centrifuge experiments of continental scale tectonics in Asia, Bull. Geol. Instit. Univ. Uppsala, 14, 115-128, 1988.

Peltzer, G., and P. Tapponnier, Formation and evolution of strike-slip faults, rifts and basins during the India-Asia collision: An experimental approach, J. Geophys. Res., 93, 15095-15117, 1988.

Peltzer, G., P. Tapponnier, and P. Cobbold, Les grands décrochements de l'Est asiatique, évolution dans le temps et comparaison avec un modèle expérimental, C. R. Acad. Sci. Paris, 294, 1341-1348, 1982.
Rangin, C., and E. A. Silver, Neogene tectonic evolution of the CelebesSulu basins: New insights from Leg 124 drilling, Proc. Ocean Drill. Program, Sci. Results, 124, 51-63, 1991.

Rangin, C., J.-F. Stéphan, and C. Müller, Middle Oligocene oceanic crust of South China Sea jammed into Mindoro collision zone (Philippines), Geology, 13, 425-428, 1985.

Rea, D. K., Evolution of the East Pacific Rise between $3^{\circ} \mathrm{S}$ and $13^{\circ} \mathrm{S}$ since the middle Miocene, Geophys. Res. Lett., 5, 561-564, 1978.

Royer, J.-Y., and T. Chang, Relative plate motion between India and Australia during the past $20 \mathrm{My}$ : Implications for the deformation of the Indo-Australian plate, J. Geophys. Res., 96, 11779-11802, 1991.

Ru, K., and J. D. Pigott, Episodic rifting and subsidence in the South China Sea, Am. Assoc. Pet. Geol. Bull., 70, 1136-1155, 1986.

Schärer, U., P. Tapponnier, L. Lacassin, P. H. Leloup, D. Zhong, and S. Zhi, Intraplate tectonics in Asia: A precise age for large-scale Tertiary movement along the Ailao Shan-Red River shear zone, China, Earth Planet. Sci. Lett., 97, 65-77, 1990.

Schmidtke, E. A., M. D. Fuller, and R. B. Haston, Paleomagnetic data from Sarawak, Malaysian Borneo, and the late Mesozoic and Cenozoic tectonics of Sundaland, Tectonics, 9, 123-140, 1990.

Schouten, J. A., A fundamental analysis of magnetic anomalies over oceanic ridges, Mar. Geophys. Res., 1, 1-144, 1971.

Sloan, H., and P. Patriat, Kinematics of the North American-African Plate boundary between $28^{\circ}$ and $29^{\circ} \mathrm{N}$ during the last $10 \mathrm{Ma}$ : Evolution of the axial geometry and spreading rate and direction, Earth Planet. Sci. Lett., 113, 323-341, 1992.

Stein, S., H. J. Melosh, and J.-B. Minster, Ridge migration and asymmetric seafloor spreading, Earth Planet. Sci. Lett, 36, 51-62, 1977.

Su, D. Q., N. J. White, and D. P. McKenzie, Extension and subsidence of the northern margin of the South China Sea, Terra Abstr., 1, 75, 1989.

Tapponnier, P., and P. Molnar, Active faulting and Cenozoic tectonics of China, J. Geophys. Res., 82, 2905-2930, 1977.

Tapponnier, P., G. Peltzer, A. Y. Le Dain, R. Armijo, and P. Cobbold, Propagating extrusion tectonics in Asia: New insights from simple experiments with plasticine, Geology, 10, 611-616, 1982.

Tapponnier, P., G. Peltzer, and R. Armijo, On the mechanics of the collision between India and Asia, in Colliston Tectonics, edited by M. P. Coward and A. C. Ries, Geol. Soc. Spec. Publ., 19, 115-157, 1986.

Tapponnier, P., R. Lacassin, P. H. Leloup, U. Sharer, D. Zong, H. Wu, X. Liu, S. Ji, L. Zhang, and J. Zhong, The Ailao Shan / Red River metamorphic belt: Tertiary left-lateral shear between Indochina and South China, Nature, 343, 431-437, 1990a.

Tapponnier, P., R. Armijo, I. Manighetti, and V. Courtillot, Bookshelf faulting and horizontal block rotations between overlapping rifts in Southern Afar, Geophys. Res. Lett., 17, 1, 1-4, 1990 b.

Tapscott, C. R., P. Patriat, R. L. Fisher, J. G. Sclater, H. Hoskins, and B. Parsons, The Indian Ocean triple junctions, J. Geophys. Res., 85, $4723-4739,1980$

Taylor, B., and D. E. Hayes, The tectonic evolution of the South China Basin, in The Tectonic and Geologic Evolution of Southeast Asian Seas and Islands, Part 1, Geophys. Monogr. Ser., vol. 23, edited by D. E. Hayes, pp. 89-104, AGU, Washington, D. C., 1980.

Taylor, B., and D. E. Hayes, Origin and history of the South China Basin, in The Tectonic and Geologic Evoluton of Southeast Asian Seas and Islands, Part 2, Geophys. Monogr. Ser., vol. 27, edited by D. E. Hayes, pp. 23-56, AGU, Washington, D. C., 1983.

Tisseau, J., and P. Patriat, Identification des anomalies magnétiques sur les dorsales à faible taux d'expansion: Méthode des taux fictifs, Earth Planet. Sci. Lett., 52, 381-396, 1981.

Watanabe, T., M. G. Langseth, and R. N. Anderson, Heat flow in backarc basins of the western Pacific, in Island Arcs, Deep Sea Trenches and Back-Arc Basins, Maurice Ewing Ser., vol. 1, edited by M. Talwani and W. C. Pitman III, pp. 137-161, AGU, Washington, D. C., 1977.

Zhang Wen You, The marine and continental tectonic map of China and its environs, scale 1:5,000,000, Science Press, Beijing, China, 1983.

A. Briais, Observatoire Midi-Pyrénées, GRGS, 18, Ave Edouard Belin, 31055 Toulouse Cédex, France.

P. Patriat and P. Tapponnier, Institut de Physique du Globe, Boîte 89, 4, Place Jussieu, 75252 Paris Cédex 05, France.

(Received August 20, 1991;

revised August 3, 1992;

accepted September 18, 1992.) 